NBER WORKING PAPER SERIES

\title{
ON THE DETERMINANTS OF MORTALITY REDUCTIONS IN THE DEVELOPING WORLD
}

Rodrigo R. Soares

Working Paper 12837

http://www.nber.org/papers/w12837

\author{
NATIONAL BUREAU OF ECONOMIC RESEARCH \\ 1050 Massachusetts Avenue \\ Cambridge, MA 02138 \\ January 2007
}

I owe special thanks to Cassio Turra for numerous detailed comments. The paper also benefited from suggestions from Gary Becker, William Maloney, Samuel Preston, Rati Ram, and seminar participants at the UN-WIDER Conference "Advancing Health Equity." The usual disclaimer applies. The views expressed herein are those of the author(s) and do not necessarily reflect the views of the National Bureau of Economic Research.

(C) 2007 by Rodrigo R. Soares. All rights reserved. Short sections of text, not to exceed two paragraphs, may be quoted without explicit permission provided that full credit, including $\odot$ notice, is given to the source. 
On the Determinants of Mortality Reductions in the Developing World

Rodrigo R. Soares

NBER Working Paper No. 12837

January 2007

JEL No. I10,I18,J1

\begin{abstract}
$\underline{\text { ABSTRACT }}$
This paper presents and critically discusses a vast array of evidence on the determinants of mortality reductions in developing countries. We argue that increases in life expectancy between 1960 and 2000 were largely independent from improvements in income and nutrition. We then characterize the age and cause of death profile of changes in mortality and ask what can be learned about the determinants of these changes from the international evidence and from country-specific studies. Public health infrastructure, immunization, targeted programs, and the spread of less palpable forms of knowledge all seem to have been important factors. Much of the recent debate has revolved around antagonistic approaches, which are not supported by the evidence discussed here. Finally, the paper suggests that the evolution of health inequality across and within countries is intrinsically related to the process of diffusion of new technologies and to the nature of these new technologies (public or private).
\end{abstract}

Rodrigo R. Soares

Department of Economics

University of Maryland

3105 Tydings Hall

College Park, MD 20742

and NBER

soares@econ.umd.edu 


\section{Introduction: A Closer Look at Life Expectancy Changes}

The last century witnessed profound transformations in the living conditions faced by the vast majority of human beings. Income per capita in the world is estimated to have risen fivefold in the period from 1900 to 2000. Life expectancy at birth in developed countries rose from around 45 in end of the $19^{\text {th }}$ century to above 75 in 2000 . For many developing countries, gains in life expectancy just in the forty-year interval between 1960 and 2000 were above 20 years (see Maddison, 2004, Keyfitz and Flieger, 1968, and World Bank, 2005).

Traditionally, changes in health have been treated as intrinsically linked to income. Therefore, growth has been seen as the cause of improved health, through improved nutrition and higher demand for health services. Though this relation is clearly present, social scientists have become increasingly aware that this view gives an incomplete picture of reality. Several important dimensions of human welfare, including life expectancy, have become gradually dissociate from income. Figure 1 portrays the cross-country relationship between income per capita and life expectancy at birth in 1960, 1990 and 2000. At any point in time, there is a clear positive correlation between the two variables (expressed by the logarithmic curves fitted to the data). Nevertheless, the figure shows a positive shift in this relationship throughout the period. This phenomenon was first noticed by Preston (1975), and seems to be happening at least since 1930. For constant levels of income, life expectancy has been rising, and particularly so for poorer countries. After 1990, the devastating effect of AIDS in Africa changed this trend for the very low income levels, and halted the shift that had been observed in the previous 50 years.

This figure stresses the fact that a significant portion of the recent changes in life expectancy has been orthogonal to changes in income. It is also related to the distinct behavior of cross-country inequality in income and life expectancy observed in the post-war period. Table 1 , reproduced here from Becker et al (2005), presents a series of inequality measures for income per capita and life expectancy at birth, for the years 1960, 1990, and 2000.These data, as previous research has found, show that, by any measure, there is no evidence of reduction in income inequality across countries up to the 1990's. During the 1990's, due mainly to the experiences of China and India, there is a significant reduction in the cross-country dispersion in income per capita (without these two countries, income inequality is stable between 1990 and 2000). In the case of life expectancy, the evidence is diametrically opposite. By any measure, life 
expectancy inequality declines substantially over the whole period, but the decline in health inequality is concentrated entirely between 1960 and 1990. After that, the effects of AIDS in Africa are felt, and inequality increases slightly between 1990 and 2000 (Vallin and Meslé, 2004 and Ram, 2006 show that, excluding Sub-Saharan countries from the sample, there are significant reductions in life expectancy inequality also between 1990 and 2000). ${ }^{1}$

Figure 2 illustrates this point further by plotting the regression to the mean in life expectancy between 1960 and 2000 (change in life expectancy against life expectancy in 1960). During this forty-year period, countries starting with high life expectancy levels tended to gain less in terms of life expectancy than countries starting with low life expectancy. According the un-weighted regression line in Figure 2 (as opposed to the weighted results presented in Table 1), life expectancies 10 years higher in 1960 were associated, on average, with gains in life expectancy 1.5 year lower in the following 40 years. But the average relation over the entire period hides radical changes taking place within specific intervals. Figure 3 breaks down the regression to the mean observed in Figure 2 into periods between 1960 and 1990, and 1990 and 2000. In the first period, regression to the mean was stronger and more homogeneously distributed than in Figure 2, while in the second period the trend was completely reversed.

The destabilizing nature of the changes observed in the beginning of the 1990's becomes even more obvious once we look at this same type of decomposition for five-year consecutive intervals (Figure 4). From 1960 up to the 1990’s, there is a striking stability in the relationship between initial life expectancy and the change in life expectancy observed in the following five years. This relation is characterized by a positive slope for very low levels of initial life expectancy (below fifty years), with higher initial life expectancy associated with higher gains in life expectancy. For initial life expectancy above intermediary levels, this relation becomes negative, and higher initial life expectancy is associated with lower life expectancy gains. The relation between initial life expectancy and gains in life expectancy in the following five years remains virtually identical in the thirty-year interval between 1960 and 1990. Given its dynamic nature, such a stable relationship necessarily implies regression to the mean in life expectancy over the long run. Together with the evidence from Table 1, we also know that this pattern ended

\footnotetext{
${ }^{1}$ Both these trends have been noticed before in the literature. In relation to income, see, for example, Barro and Sala-i-Martin (1995), de la Fuente (1997), Mankiw, Romer, and Weil (1992), Quah (1996), Parente and Prescott (1993), and Sala-i-Martin (2002), and in relation to life expectancy, see Bourguignon and Morrison (2002), Goesling and Firebaugh (2004), Neumayer (2003), Sap and Smith (2002), Younger (2001), and Kenny (2005).
} 
up translated into convergence and reduced life expectancy inequality between 1960 and 1990 . As countries starting with low life expectancy moved from left to right over the horizontal axis, they eventually reached a period of very large gains that led to convergence toward higher levels of life expectancy.

The stability of this relation over the thirty-year period in question suggests that a continuous and natural process of change was underway. Riley (2005a) highlights the puzzling stability and homogeneity of the process of mortality reductions in the post-war period, despite different patterns of access to water, sanitation, education, income, and housing across the various countries. Though by the mid 1980's researchers expressed concerns about the possibility of a collapse in the trend of mortality declines in developing countries, most countries sustained substantial gains in life expectancy up to 1990 (Hill and Pebley, 1989 and Riley, 2005a). In reality, apart from Eastern Europe and Sub-Saharan Africa, most countries experience substantial gains in life expectancy up to today (Riley, 2005a). Nevertheless, around 1990 and before all countries could fully benefit from the improvements, the emergence of AIDS and - to a much lesser extent - the institutional turmoil in post-communist countries, led to the collapse of the regression to the mean relationship that was kept untouched at least since 1960 (this point is explored in further detail by Ram, 2005 and 2006). The effect of AIDS on the cross-country behavior of life expectancy after 1990 is overwhelming, and it can be seen from the fact that all countries experiencing declines in life expectancy above 5 years in Figure 3(b) are countries under siege by the epidemic (Botswana, Lesotho, Namibia, Swaziland, South Africa, Zambia, and Zimbabwe; see Philipson and Soares, 2005). The effect of AIDS at the end of the $20^{\text {th }}$ century dwarves any other change observed in the period and completely destabilizes a regression to the mean relationship that seemed to be almost technological in nature. Though the importance of AIDS in this context is self evident, the specific determinants of the previous improvements in life expectancy in the developing world remain unknown.

The goal of this paper is to discuss the determinants of the improvements in life expectancy observed in the developing world during the post war period. Recent estimates suggest that longevity has indeed been a quantitatively important component of the overall gains in welfare during the twentieth century, both within and across countries (see Cutler and Richardson, 1997, Nordhaus, 2003, and Murphy and Topel, 2003, Burström, Johannesson, and Diderichsen, 2003, and Becker et a., 2005). Therefore, understanding the determinants of these 
changes has immediate implications for both research and policy. From a research perspective, pinning down the factors determining the observed reductions in mortality may shed light on the interactions between health, human capital, and income, and on their relative importance for the process of economic development and social change. From a policy perspective, it may help maximize the impact of future health interventions in countries that still lag behind in terms of health improvements. In particular, this knowledge may be fundamental in designing policies to rescue Sub-Saharan Africa from its present state. ${ }^{2}$

The structure of the remainder of the paper is outlined as follows. Section 2 summarizes a large body of evidence from different sources in order to draw a broad picture of the nature, age and cause of death profile of recent reductions in mortality in the developing world. Following, section 3 raises some theoretical considerations on the determinants of mortality that are suggested by this general picture. Sections 4 and 5 then present the empirical evidence currently available on the specific determinants of reductions in mortality. In particular, section 4 discusses the aggregate evidence, paying attention to the determinants of the diffusion of health technologies and to cross-country correlates of mortality, while section 5 analyzes the microevidence from region and country-specific studies. Finally, Section 6 concludes the paper by tying together its different parts and, drawing on the various pieces of evidence available, giving a wide-ranging interpretation of the process of mortality reductions across the world.

\section{The Pattern of Mortality Reductions in Developing Countries}

As noticed in the introduction, a large part of the life expectancy gains experienced by developing countries in the post-war period seems to be unrelated to improvements in income or, more generally, material living conditions. In Latin America, for example, this is clearly exemplified by the experiences of Bolivia, Honduras, and Nicaragua, where modest - or even negative - economic growth was accompanied by gains in life expectancy at birth of the order of 20 years. This is by no means a phenomenon restricted to Latin America. Figure 1 shows that, in a broad cross-section of countries, life expectancy has been increasing for constant levels of

\footnotetext{
${ }^{2}$ Ezzati et al (2003), for example, estimate that $25 \%$ of all deaths in Sub-Saharan Africa are caused by conditions for which effective interventions already exist (respiratory infections, diarrheal diseases, low birth weight and malaria), with an additional 9\% due to AIDS.
} 
income. In this section, we discuss the nature of recent changes in mortality and analyze their profile in terms of age and cause of death.

\subsection{Nature of Mortality Changes}

The shift in the income-life expectancy profile observed at least since 1930 does not imply the absence of a relationship between income and mortality. In reality, Figure 1 shows precisely that at any point in time there is a close positive association between income per capita and life expectancy at birth. This relationship reflects to a great extent differential nutrition and consumption of health services across different income levels. The role of income in determining mortality, mainly through nutrition, was extensively discussed by Fogel (see, for example, Fogel, 1994 and 2004). His highly controversial analysis tends to attribute an extremely large fraction of the reductions in mortality to improved nutrition. But even so, he claims that nutrition explains almost all the mortality reductions in some European countries up to the end of the $19^{\text {th }}$ century, but only $50 \%$ after that. Starting in the beginning of the $20^{\text {th }}$ century, even according to Fogel's extreme calculations, roughly half of the changes in mortality cannot be accounted for by improved nutrition, and seem to come from sources unrelated to improved material conditions. This is also what Figure 1 reveals. Though nutrition and consumption of health services imply a positive relation between income and life expectancy, some type of technological change has taken place, so that for constant income life expectancy has been rising.

Evidence from developing countries also supports the idea that the shift in the incomelife expectancy profile is not an artifact of improved nutrition for constant levels of income. Table 2, reproduced from Preston (1980, p.305), contains information on life expectancy at birth in 1940 and 1970, for countries at different income and nutrition levels. Life expectancy gains took place in all the nutrition brackets shown in the table. For the lowest nutrition group (less than 2,100 calories daily), there was an increase of 10 years in life expectancy at birth. Recent data also confirms this same pattern for the period between 1960 and 2000. Figure 5 first shows that, for constant levels of income, nutrition does seem to have improved slightly in the last forty years (as measured by daily caloric consumption). This may be the result of rising agricultural production and declining relative price of food. But the shift in the cross-sectional relationship is rather modest: typically, for constant income, calorie consumption increased by little more than $200 \mathrm{kcal}$ a day. This is far from enough to explain the shift in the income-life expectancy profile, as becomes clear in Figure 6. This figure shows that, between 1960 and 2000, the cross-sectional 
relationship between nutrition and life expectancy at birth shifted in much the same way as the cross-sectional relationship between income and life expectancy. Between 1960 and 1990, for constant nutritional levels, life expectancy at birth raised by as much as 8 years for countries in the lowest caloric consumption range. After 1990, with the arrival of AIDS, the outward shift observed since 1960 was partially reversed, but still the relationship remained considerably above its initial profile. ${ }^{3}$

With a cross-country econometric analysis relating life expectancy improvements to income and caloric consumption, Preston (1980) concludes that approximately 50\% of the changes in life expectancy between 1940 and 1970 were due to "structural factors," unrelated to economic development or nutrition. Though this number is similar to the one obtained by Fogel (1994), Preston (1980) hypothesizes that income per capita also captures dimensions related to the provision of public health infrastructure, which are not present in Fogel's framework. Heuveline (2001) extends Preston's (1980) analysis and finds similar results for the period between 1960 and $2000 .^{4}$

Other evidence also supports the idea that improvements in nutrition and income are insufficient to explain the gains in mortality observed in recent decades. Palloni and Hill (1997), for example, analyze the pattern and extent of mortality changes in Latin America between 1950 and 1990. Though concluding that mortality does respond to short term economic crisis (mainly among children, and from diarrhea and tuberculosis), they show that these responses are very small and quantitatively irrelevant when compared to the historical trend (though morbidity changes may be substantial). Caldwell (1986) discusses particular historical experiences of “mortality breakthroughs” that were not accompanied by similar economic growth, while Hill and Pebley (1989), Easterling (1996), Deaton (2004), and Cutler et al (2006), among others, present other types of arguments, all concluding that the relation between economic growth, nutrition, and mortality is far from enough to explain the improvements in life expectancy observed during the $20^{\text {th }}$ century.

\footnotetext{
${ }^{3}$ The basic profile of the shift in these curves does not depend on the functional forms adopted. Logarithmic curves would lead to qualitatively similar results.

${ }^{4}$ In reality, as discussed by Mosley (1984), infection can hinder absorption of nutrients, being under certain circumstances a cause rather than a consequence of malnutrition. Obviously, the interaction between these two dimensions is complex, with each one reinforcing the other.
} 
In order to better understand this pattern of gains in life expectancy, we first explore in more detail the profile of changes in age and cause of death and how it relates to the process of reductions in mortality.

\subsection{Age and Cause of Death}

Changes in the age and cause-distribution of mortality characterize the progression of the demographic transition or, similarly, what has been termed the "epidemiological transition.” The term epidemiological transition was first coined by Omran (1971), as a description of the process of change in leading causes of death that takes place as mortality reductions progress, from infectious diseases to chronic non-transmissible diseases (see discussion in Riley, 2001). Associated with this change in leading causes of death, there is also a shift in the age-distribution of deaths, from mostly concentrated at younger ages to older ages, and eventually to a distribution where child and infant mortalities become relatively unimportant. ${ }^{5}$

This process of transformation has been widely documented in the now developed world, for cases where long-term mortality data are available. Preston and Haines (1991), for example, analyze changes in child mortality in the US around the end of the $19^{\text {th }}$ century. They show that, between ages 0 and 4, infectious diseases of the gastro-intestinal and respiratory tracts were responsible for $45 \%$ of all deaths, with premature birth, malformation, and childhood diseases accounting for an additional 30\%. Improvements in the period were driven mainly by practices introduced with the acceptance of the germ theory of disease, including boiling milk and sterilizing bottles, washing hand before handling food, isolating sick family members, etc. This marked the initial stages of the evolution towards the systematic improvements in life expectancy observed during the $20^{\text {th }}$ century.

Cutler and Meara (2001) complement this analysis by discussing the changes in the cause and age distribution of mortality in the US throughout the $20^{\text {th }}$ century. They show that during the first half of the century infectious diseases were the leading cause of death. During this period, nutrition and public health interventions were the most important factors determining reductions in mortality, and these reductions were mostly concentrated on mortality from infectious diseases at younger ages (80\% of the life expectancy gains concentrated before age 45 ,

\footnotetext{
${ }^{5}$ Today, the sequence of events described by Omran (1971) is not regarded as fixed, but rather as a consequence of technological advances taking place at different moments in history. Nevertheless, since it does give an accurate description of events in the historical experiences of mortality reduction discussed in this section, we keep his definition for now and save discussion on its merits to later on (section 6).
} 
and roughly 65\% concentrated before age 14; reduced deaths from infectious diseases were responsible for three-quarters of the gains in life expectancy in the period).

Between 1940 and 1960, infectious diseases continued to play an important role, but specific medical innovations (mainly antibiotics) became important factors in determining mortality reductions. In this period, mortality changes were more evenly distributed across the different age groups and were strongly concentrated in diseases for which new drugs became available.

Finally, in the period between 1960 and 1990, mortality reductions shifted towards more sophisticated and technologically intensive medical advances. These were concentrated on reduced mortality from heart and circulatory diseases at older ages and on mortality due to low birth weight at earlier ages. In this last period, changes in mortality above age 45 accounted for two-thirds of the overall gain in life expectancy. ${ }^{6}$

These authors show that major reductions in mortality from infectious diseases started taking place well before specific medical treatments became available. This is in line with the evidence presented by Cutler and Miller (2005), who estimate that the introduction of clean water technologies was responsible for $43 \%$ of the reductions in mortality observed in major American cities between 1900 and 1936. For infant mortality alone clean water is estimated to have been responsible for $74 \%$ of the reductions in mortality, and for typhoid fever, near complete eradication. Their particular point estimates should be regarded with caution, since the authors use lagged dependent variables together with fixed effects, leading to inconsistent estimates. But, nevertheless, their descriptive analysis and discussion gives strong support to the role played by the introduction of clean water in the reduction of mortality across large American cities, as also suggested by Easterlin (1996). In addition, they present evidence indicating that poorer populations benefited more from clean water systems than richer population, even though they were not the first group affected by it, therefore stressing the public good dimension of public health technologies.

Historical evidence from England tells a similar story. McKeown and Record (1962) discuss the causes of death behind the improvements in life expectancy observed in England and

\footnotetext{
${ }^{6}$ Reductions in adult mortality can be also caused by previous reductions in child mortality and morbidity, in addition to specific medical innovations. For example, heart problems in adulthood may be associated to childhood rheumatic fever. In this sense, part of the reductions in adult mortality observed during the later stages of the epidemiological transition may be just dynamic implications of early improvements in child health.
} 
Wales between 1837 and 1900 . They conclude that tuberculosis was responsible for $45 \%$ of the mortality reduction, while typhus and typhoid fever (22\%), scarlet fever (19\%), cholera, dysentery and diarrhea (8\%), and smallpox (6\%) were also important sources of life expectancy improvements. Though McKeown (1976) eventually defended the idea that nutrition was the main determinant of susceptibility to diseases and, therefore, that improvement in living conditions was the key determinant of mortality reductions, his first interpretation gave more credit to public policy. For typhus, typhoid fever and cholera, he initially conjectured that reductions in mortality were mostly due to sanitary reforms, while for scarlet fever they might had been affected by a change in the interaction between infectious agent and human host. The effect of direct treatment of diseases on overall mortality was relatively small, given that explicit therapies did not exist but for smallpox. ${ }^{7}$ In the case of tuberculosis, there was no precise cause identified for the improvements in mortality. Since changes in the interaction between bacillus and men were unlikely in this case (men had been exposed to it for centuries), McKeown and Record (1962) concluded that most of the mortality reductions related to tuberculosis should be attributed to improving living conditions, mainly through improved diet. Overall, they argued that living conditions probably contributed roughly $50 \%$ for the total reduction in mortality in the period (tuberculosis and some effect on typhus and typhoid fever), while sanitary reforms were responsible for other 25\% (most of reductions through typhus, typhoid fever, and cholera).

Following chronologically, Livi-Bacci (2001) discusses the determinants of mortality in England from the end of the $19^{\text {th }}$ century until 1951. Over this period, England gained more than 26 years in life expectancy at birth. Roughly 55\% of these gains can be attributed to reductions in mortality due to infectious diseases, bronchitis, pneumonia, and influenza, with diseases of the infancy, diarrhea, and enteritis being responsible for other 13\% (p.96).

In the case of Italy, gains of 30 years in life expectancy at birth were registered between the end of the $19^{\text {th }}$ century and the middle of the $20^{\text {th }}$ century. As in England, roughly $55 \%$ of these gains can be attributed to reductions in mortality from infectious diseases, bronchitis, pneumonia, and influenza, with other diseases of the infancy, diarrhea, and enteritis being responsible for other 18\%. By 1981, Italy had already shown substantial reductions in mortality

\footnotetext{
${ }^{7}$ Edward Jenner developed a vaccine for smallpox in 1796, after when incidence of infection in Europe declined. The decline was somewhat uneven though, because of problems with vaccination and because the immunity lasted for about ten years only. The vaccine consisted of the subcutaneous inoculation of patients with the milder cowpox virus.
} 
throughout the entire age distribution, with the probability of survival from birth to age 15 increasing from $58 \%$ in 1881 to $98 \%$ in 1981 , survival to age 50 increasing from $41 \%$ to $94 \%$, and survival to age 80 increasing from $6 \%$ to $42 \%$ (Livi-Bacci, 2001, p.113).

The well-documented historical experience of developed countries sheds light on the potentially important forces behind the changes observed in developing countries, even when these forces cannot be directly observed. In addition, it hints at the path that may lay ahead (despite concerns related to the abusive use of this view raised by Palloni, 1981). As long as we can characterize the reductions in mortality in terms of underlying causes of death or age groups, and the technologies available at a given point in time, the evidence discussed above will suggest the possible candidates for main determinants of mortality reductions.

In this respect, the first significant effort to identify the diseases responsible for mortality reductions in the developing world was undertaken by Preston (1980). Table 3 (reproduced from Preston, 1980) presents the approximate percentage of mortality decline in less developed countries between 1900 and 1970 accounted for by different diseases. Preston argues that, apart from influenza/pneumonia/bronchitis, preventive measures were probably the most effective ones in determining mortality reductions. Large-scale immunization of populations and improvements of water supply and sewage disposal took place in several less developed countries throughout the second half of the twentieth century. The author argues that the direct impact of economic development in reducing mortality probably operated mostly through influenza/pneumonia/bronchitis, for which there was no effective deployment of preventive measures and treatment only became widely available later on in the period. For infectious and diarrheal diseases, improvements came through development of water supply, sewerage, and immunization (Preston, 1980, p. 313). Preston's (1980) interpretation considers public health infrastructure (water and sanitation) as part of the process of economic development and, therefore, does not include it in what he calls "structural factors." The table suggests that this view generates numbers similar to the income-nutrition-mortality analysis, with roughly $50 \%$ of the life expectancy gains being unrelated to simple improvements in material conditions (incidentally, this result is also similar to that of Fogel's, 1994, even though the exercises are not strictly comparable; Fogel considers only the role of nutrition, while Preston, 1980 considers that development refers to income, nutrition, and improvements in health infrastructure). 
Palloni and Wyrick (1981) find similar evidence for the case of Latin America between 1955 and 1973. They show that reductions in mortality due to infectious diseases, influenza/pneumonia/bronchitis, and diarrhea were the main factors contributing to the gains in life expectancy observed in the period. Factors unrelated to living standards seem to have been particularly important in regions where malaria was endemic, and where other infectious diseases were more prevalent. In line with the results mentioned above, they find that $55 \%$ of the reductions in mortality were due to exogenous factors, while only $45 \%$ came from improvements in living standards.

The relation between changes in mortality by cause of death and methods of prevention and treatment portrayed in Table 3, and discussed in the previous paragraphs, is similar to that suggested by Cutler and Meara (2001). In general, changes in mortality by cause of death are also intimately linked to changes in mortality by age of death, reflecting the epidemiological stage of development of a specific society (see Palloni, 1981). At a point in time, both of these will be related to the type of health technology available and employed in each particular case. In this sense, the historical pattern observed in developed countries mirrors the cross-country differences in mortality changes observed in the post-war period. Mortality reductions experienced by developing regions in the last 40 years are very similar to the ones experienced by the US in the beginning of the $20^{\text {th }}$ century, while the ones experienced by developed regions look very much like the ones experienced by the US in recent years.

Table 4, calculated from the results presented in Becker et al (2005), illustrates this point. These results refer to the period between 1965 and 1995, and are based on a relatively small sample (49 countries), so that they are only representative of middle-range developing and developed countries. The table shows how the pattern of cause and age-specific life expectancy gains changes across different development levels (Sub-Saharan Africa and South Asia are absent from the sample). In the poorest region (Middle East and North Africa), life expectancy gains are almost entirely concentrated on infectious diseases of the respiratory and digestive tract, and congenital anomalies and perinatal period conditions. As a result, $90 \%$ of the mortality reductions are concentrated before age 19. As the development level increases, mortality shifts monotonically from early to old ages (following, in order, Latin America and the Caribbean, East Asia and the Pacific, Europe and Central Asia, and North America). In the case of North 
America, $60 \%$ of the mortality reductions are attributed to heart and circulatory diseases and nervous systems and senses organs conditions, all concentrated above age 50.

Both the within country historical trends in mortality, and the cross-country variation in life expectancy gains, suggest a process of mortality reductions that describes the progression of a country through the different stages of the epidemiological transition. Nevertheless, there is no agreement as to the specific factors that determined these reductions. Following, we raise some theoretical considerations suggested by the stylized facts discussed in this section and confront it with the evidence currently available on the specific determinants of mortality reductions in developing countries.

\section{Theoretical Considerations}

The evidence discussed in the previous sections suggests that "structural factors," not directly related to economic development, were responsible for a substantial fraction of the recent reductions in mortality in developing countries. Still, a question that remains open is exactly what these "structural factors" were. Since significant reductions in mortality took place at very low income levels and with minimal expenditures on health, it is believed that diffusion of new technologies (maybe incorporated in ideas, personal health practices and public goods) must have played an important role.

It may therefore be tempting to draw on the well-established trade literature on international diffusion of productive technologies in order to guide the discussion on the determinants of mortality reductions (for an extensive review of this literature, see Keller, 2004). A central idea in the trade literature is that technology is embodied in goods. Therefore, when a country imports a capital good from a technology-generating center, it immediately becomes more productive, since the new capital good incorporates a more efficient technology and its use reflects that. In this case, improved productivity is simply a result of the use of a better intermediate good, not necessarily implying the understanding of this new technology or the capacity to reproduce it on the part of the user (importing country). In addition, this literature stresses the possibility that researchers in a given country may benefit from the R\&D generated elsewhere, through increases in the stock of knowledge available in society. Of course, the possibility of this second mechanism rests on the nature of the R\&D in foreign countries (nonexcludable) and on the capacity of the home country to access and “absorb” this new knowledge. 
Though the diffusion of productive technologies may indeed offer some insights into the process of diffusion of health technologies, there are key aspects of the latter that are somewhat specific to it. First, to a great extent, health is the outcome of a household production process. This is true in terms of household behaviors related to personal hygiene, handling and preparation of food, treatment of water, and handling of these same issues in raising offspring. In this perspective, absorption of technology demands absorption of knowledge on the part of the consumer/producer herself. This aspect is probably more important at low levels of income (or high levels of mortality), so that the idea of embodiment of new technologies in goods purchased on the market is likely to be relatively unimportant in these cases. As health improvements become more dependent on specific medical interventions, as in the examples cited by Deaton (2004), the relative importance of the "embodied technology" idea is therefore likely to increase. This would probably take place mainly through the imports of medicines and medical equipment, both of which may incorporate new technologies leading to higher productivity in terms of health outcomes.

A second specific aspect is the fact that health technologies have a large public good dimension. Basic ideas and knowledge, in particular, are extreme versions of this notion. For example, as soon as the germ theory became widely accepted, its main implications became publicly available to agents who had the capacity to absorb them. In reality, this is the most extreme version of a real public good, where the idea itself is literally non-excludable, non-rival, and not subject to any type of congestion. ${ }^{8}$ In typical health technologies, however, this is not the case. But externalities and traditional public goods are still very important when discussing, among other things, the development of new medicines and the implementation of public health programs. Particularly, several public health programs are implemented precisely because private provision is not viable or inefficient. This is the case in relation to the provision of clean water and sewerage systems, vaccination campaigns, environmental regulations, etc. In some of these examples, technologies are not particularly sophisticated and goods do not incorporate new

\footnotetext{
${ }^{8}$ Mokyr (1998) discusses the process of advances in knowledge in medical sciences and the technological innovations induced by it. In another paper, Mokyr (2000) discusses in detail the final acceptance of the germ theory in the end of the $19^{\text {th }}$ century, and the implications it had in terms of changes in personal and public health practices. He also points to the fact that the beginning of the health revolution, related to the early recognition of "cleanliness" as a way to prevent diseases, dates back to the empirically based sanitary and hygienic movement from the early $19^{\text {th }}$ century, well before the advent of the germ theory.
} 
knowledge, but implementation involves large fixed costs and very low marginal costs, and is the outcome of an intricate political process that is affected by many other considerations. In other examples, goods do incorporate new technologies, but their adoption still depends on the outcome of a centralized political process. In any case, changes depend on processes that are outside the control of any individual agent in society and that, given its political and technological nature, may be exogenous even to the economic conditions faced by the country.

Easterlin (1996 and 1999) stresses arguments along similar lines in order to draw a distinction between innovations in health technologies and in productive technologies. He suggests that the profit motive is not enough to lead to technological investments in health improvements, as opposed to technological investments in productive technologies. Because of that, mortality reductions in the past were not due exclusively to market forces. Externalities, public goods, principal-agent, and free rider problems plague the nature of investments and interventions related to health, and therefore government action or centralized provision are required for efficiency to be achieved. In some cases, efficient government action requires actual overriding of property rights and personal freedoms, such as in compulsory immunizations, sanitary reforms in slums, or sacrifice of animals due to risk of contamination (tuberculosisinfected cows in the historical example, or avian flu-infected birds in recent years). The importance of political action, together with institutional ability and willingness to implement known technologies, is also highlighted by Mosley (1984) and Cutler et al (2006).

For all these reasons, it is likely that the diffusion of health technologies depends much more on the absorption of knowledge on the part of agents and on public provision, and less on the embodiment of new technologies, than does the diffusion of productive technologies. This is particularly important for changes in mortality observed at very low levels of development, when improvements can take place even with very low expenditures on health. This logic opens space for reductions in mortality independently of improvements in income, as observed in the historical examples, but still leaves room for several alternative mechanisms through which this change could take place. Candidate mechanisms in this respect range from diffusion of pure nonrival and non-excludable knowledge, to public or international interventions focused at particular diseases, or to family and community health programs targeted at health practices within the household. 
In relation to the diffusion of knowledge, one of the most dramatic events of the last century was the acceptance of the germ theory (developed on the turn of the nineteenth to the twentieth century), which allowed for inexpensive gains in life expectancy via simple preventive measures (see Vacher, 1979, Ram and Schultz, 1979, Preston, 1980 and 1996, and Ruzicka and Hansluwka, 1982, Easterlin, 1999, and Mokyr 2000). Simple changes on public practices and personal health behavior, brought about by knowledge previously inexistent, allowed for significant reductions in mortality rates at relatively low costs (Preston, 1996). These new technologies came in the form of both changes in personal practices and large scale interventions. In this context, the role played by developed countries in information dissemination and program implementation is thought to have been particularly important. Health programs became increasingly dissociate of countries' economic conditions, and more dependent on the concerns of the developed world. Even though the monetary value of the help was typically small, the largest contribution came in the form of development of low cost health measures, training of personnel, initiation of programs, and more effective and specific interventions (see Preston, 1980, and Ruzicka and Hansluwka, 1982).

International mobilization was also important in determining the possibility and effectiveness of the fight against specific conditions and diseases. One of the most celebrated examples in this respect is the United Nations' Expanded Program on Immunization (EPI). The EPI was implemented in 1974 with the goal of bringing previously available vaccines against various diseases (measles, diphtheria, pertussis, tetanus, tuberculosis, and polio, among others) to the disadvantaged population of developing countries. In countries reached by the program, immunization rates skyrocketed in a matter of few years, while infection rates dropped immediately. Among other things, the EPI reached virtual eradication of polio from the Americas in 1994, and raised immunization rates for the six target diseases mentioned above from 5\% of the world's newborns in 1974 to more than 80\% in 2000 (WHO, 2003 and World Bank, 2005). Country specific interventions focused particularly on endemic conditions and on public health infrastructure were also successful, as exemplified by the case of malaria in Guyana, Guatemala, Mauritius, Mexico, Sri Lanka, and Venezuela (see Gray, 1974).

Still, the potential importance of community and family level interventions should not be minimized. In reality, the presumed importance of these factors led some researchers to raise concerns about the effectiveness of narrow interventions focused on the delivery of specific 
technologies (see, for example, Mosley, 1984, or discussion in Hill and Pebley, 1989). Their main objection was that, for example, vaccination for one disease might simply increase mortality by competing causes of death for immediate later ages, having therefore a relatively modest impact on overall life expectancy. According to this view, immunization or the use of "palliative measures" (as rehydration therapy) would just postpone the death of a child, and increase mortality by other causes. An adequate health intervention would therefore require a broader approach to the problem, taking into account the social factors conditioning mortality in different communities. In practical terms, this line of reasoning highlights the relevance of maternal education and household production as determinants of child mortality, and the importance of community-level interventions focused on the provision of comprehensive primary care. In addition, it stresses the cultural dimension as a key determinant of the success of any program (Mosley, 1984).

Taking into account these different candidates for determinants of reductions in mortality, the next sections look at the evidence currently available from both cross and within country perspectives.

\section{International Evidence}

\subsection{Aggregate Patterns}

In order to clarify the pattern of changes hidden behind the life expectancy gains in developing countries, Table 5 presents age-specific mortality rates by regions of the world. The table presents mortality rates before ages 1 and 5 (per 1,000 live births), and between ages 15 and 60 (per 1,000 adults), for the years 1960 and 2000.

The mortality data used here are from the World Bank's World Development Indicators. Health related data presented in the World Development Indicators are from the United Nations Statistics Division's Population and Vital Statistics Report, from national statistical offices, from the Demographic and Health Surveys, or from UNICEF. A word of caution is in place here. Though most of the primary vital statistics used in these calculations come from national civil registration systems, the degree of coverage and information detail of the systems may vary substantially from country to country. When these statistics are not available or are incomplete, periodic surveys, projections, and censuses are used to complement the data (United Nations, 2005). Most importantly, detailed age specific mortality rates are not always available and 
indirect estimations based on auxiliary data or demographic models are oftentimes used. This is not a major concern in relation to child and infant mortality, for which estimation based on survey data on number of children ever born and number of children alive give quite accurate estimates (Brass, 1975), but it can be a problem for mortality at older ages. In these cases, absence of data is usually overcome by the use of model life tables. Model life tables allow the estimation of mortality rates at adult and old ages based on the observation of a few age specific mortality numbers, and on the classification of a given population within one specific "family" of model life tables (United Nations, 1983). Though the use of indirect data in the comparison and analysis of health changes has been strongly criticized by some researchers (Musgrove, 2003), others have argued that it is an integral part of the process of evolution in the measurement of health systems performance, and it reflects the best use of the information and knowledge currently available (Brutland et al, 2003). Other public health researchers have also highlighted the importance of analyzing various dimensions of health performance, not only child and infant mortality, even if only with the limited existing information, in order to draw an adequate picture of the health status of different populations (Mathers et al, 2003a, Mathers et al, 2003b, and Bruntland et al, 2003).

Even though the application of model life tables to estimate mortality rates at certain ages may lead to inaccurate measures for one particular country, we believe that its use does not systematically bias the estimates and, thus, produces on average good descriptions of the mortality profiles observed in the world today. Keeping this limitation in mind, we look at the mortality numbers presented by the World Development Indicators as reasonable approximations to the average patterns of mortality observed in different regions of the world.

In Table 5, we see that, in developing areas, reductions in mortality were significant in every age group, though they were more extreme for infant and child mortalities. In Latin America, mortality before age 1 was reduced by $70 \%$ between 1960 and 2000, while mortality before age 5 was reduced by almost $80 \%$. At the same time, the probability of dying between ages 15 and 60 fell from 0.27 to 0.17 , corresponding to a 35\% reduction in adult mortality. In East Asia and the Pacific, mortalities before ages 1 and 5 were reduced by, respectively, 77\% and $80 \%$, while adult mortality declined by $73 \%$. Middle East and North Africa, together with South Asia, also experienced substantial mortality reductions in all age groups, though typically attaining levels somewhat higher by year 2000. The only exception to this pattern is the case of 
Sub-Saharan Africa, where reductions in infant and child mortality were more modest (both around 32\%), and reductions in adult mortality non-existent (mainly due to the effects of AIDS starting in the early 1990's).

Apart from the case of Sub-Saharan Africa, the trends observed in developing countries reflect the movement from the first stages of mortality reductions, when infant and child mortalities are the most important factors, to the second stage, when adult mortality becomes relatively more important. This can be partly inferred from the regional differences seen in the table. While developed areas (North America and Europe) start in 1960 already with levels of child mortality considerably low, the poorest areas (Sub-Saharan Africa) do not experience significant reductions in adult mortality up to the end of the period. In between, we have Latin America and the Caribbean, East Asia and the Pacific and, lagging a little behind, South Asia, all of which experienced significant declines in both adult and child mortalities. ${ }^{9}$

Within regions, differences in trends across countries can also be significant. In Latin America, for example, there are cases such as Guyana, Paraguay and Uruguay, where reductions in adult mortality have been relatively minor when compared to changes in infant and child mortalities. At the same time, in Chile, Costa Rica, Cuba, Guatemala, Mexico, Panama and Peru, adult mortality was reduced by more than $50 \%$ over the forty-year interval portrayed in the table. The only increase in mortality in Latin America during the period is registered for adult mortality in Haiti, where the number goes from 401 per 1,000 adults to 449.

Overall, the idea that infant and child mortality reductions were virtually the only causes of life expectancy gains in developing countries is mistaken. Typically, mortality reductions took place across the entire age distribution, with significant improvements in the survival of both children and adults. Undoubtedly, the extent of reduction in early mortality was astounding, and its final effect on life expectancy was probably higher than that of changes in mortality in any other age group (see Table 4, for example). But, at the same time, the probability of surviving from age 15 to age 60 increased between 10 and 45 percentage points across most of the developing world, and the extent of this change cannot be ignored.

\footnotetext{
${ }^{9}$ Adult mortality for Europe and Central Asia increases slightly between 1960 and 2000 due to the presence of some former communist countries in the sample. In these countries, the collapse of the Soviet Union was associated with significant increases in adult and old age mortality. If we look to Western Europe alone, reductions in mortality were also substantial between ages 15 and 60 .
} 
The analogy with the evidence from developed countries suggests that, in the post-war period, the developing world was in the transition between the first and second phases of the epidemiological transition. This corresponds to large reductions in mortality from infectious diseases at early ages, but already significant gains in life expectancy from other causes of death at later ages. The source and extent of the reductions in infant and child mortalities in this period (see Tables 4 and 5) suggests changes very similar to the ones observed in the US during the first half of the $20^{\text {th }}$ century. In that case, reductions in mortality were driven mainly by preventive public health interventions related to the provision of clean water (Cutler and Meara, 2001 and Cutler and Miller, 2005). But this was a consequence of the simple fact that, for most infectious diseases, alternative technologies - such as immunization or treatment (antibiotics) - were not yet widely available. In the case of developing countries in the post-war period, these technologies were already available and, in some cases, were actively subsidized or even directly implemented by international organizations (as in the example of the Expanded Program on Immunization discussed before). Some international programs, on the other hand, also provided aid for implementation of clean water systems, as the econometric evidence discussed later on addresses. So it is likely that a mixture of preventive and treatment factors - identified as important in, respectively, the first (1900-1940) and second (1940-1960) phases of the US experience - played important roles in the changes observed in developing countries between 1960 and 2000.

Tables 6 and 7 present a series of variables measuring different dimensions of health expenditures, infrastructure, and inputs for regions of the world. The information in the table is typically available for periods much shorter than the ones for which we have mortality data. The data from the World Development Indicators used here come mostly from the World Health Organization. Public expenditure data are complemented with information from the Organization for Economic Cooperation and Development, the International Monetary Fund, and the World Bank itself. Data on private expenditure in developing countries, on the other hand, are drawn largely from household surveys conducted by governments and international organizations. Information on physicians and hospital beds also use data from OECD, TransMONEE, and from individual countries. Finally, immunization data is complemented with information from UNICEF and from the Demographic and Health Surveys (World Bank, 2005). 
The shortcomings related to data quality mentioned before are potentially even more serious in cases such as immunization coverage, and hospital and physician availability. For number of physicians per capita and hospital beds, for example, definitions may vary substantially across countries and sources. The effort of developing a comparable set of metrics to evaluate and contrast the performance of health systems across countries and regions is a relatively new one, and this ends up reflected in the quality of the statistics currently available (Mathers et al, 2003a). For example, in the case of immunization, Murray et al (2003) show that the cross-country correlation coefficient between officially reported rates and rates calculated from the Demographic and Health Surveys (DHS) is only 0.45 (for DPT3 coverage in 41 countries, between 1985 and 1998). And, even though the coefficient of a regression of the officially reported rate on the DHS rate is 1.02 , the constant term is equal to 0.21 , indicating that official rates overestimate coverage rates by, on average, $20 \%$. They also show that this relation seems to be non-linear, with countries with lower coverage having official and DHS rates more closely related than countries with high coverage (where the overestimation in official rates is larger). More seriously, there is no clear pattern on the association between official and DHS rates when changes over a 5 year-period are analyzed (regression coefficient of 0.21 , with $\mathrm{R}^{2}$ equal to 0.02). Since different countries and periods of time in the World Development Indicators are covered by different sources, a detailed analysis of this type of problem in the current dataset would require an effort beyond the scope of this paper. Therefore, we follow on our discussion based on the data tabulated by the World Bank (2005), but keep in mind this limitation. In the next section, we analyze micro evidence from country-level studies to evaluate whether the conclusions suggested by this anecdotal evidence seem to be robust.

Table 6 shows that private expenditures on health in developing regions have increased, on average, on par with income, so that the GDP percentage has remained roughly stable (with the exception of East Asia and the Pacific). Public expenditures have shown a modest positive trend, leading to an increase in total expenditures on health between $0.5 \%$ and $1.3 \%$ of the GDP between 1990 and 2000. As fractions of GDP, these are levels way below the ones observed in the developed world, and quantitatively correspond to considerably low values (below \$300, as measured in 1996 international prices). Therefore, it is difficult to think that increases in expenditure would be the only underlying reason behind the changes in mortality rates (in reality, the shift in the income-life expectancy profile indicates that it is not). 
Direct access to hospitals and medical services do not seem to be important factors either. The table shows that, if anything, the availability of hospital beds per inhabitants has been decreasing in most regions of the world. This reduction probably reflects the advent of new health technologies, rather than a widespread deterioration in the provision of medical services. The physically limiting aspect of many chronic conditions, as well as the recovery period of surgical interventions, may have been significantly reduced due to the availability of new drugs and, in some cases, reduced prevalence due to other technological innovations. In addition, the number of painful or fatal diseases for which no treatment was available and hospitalization was the only alternative may also have decreased. Therefore, technological innovations are likely to have generally shifted medical interventions away from continuous medical supervision in hospitals and toward more punctual and technologically intensive care.

The factors in Table 6 that seem potentially important in explaining the gains in health in developing countries are access to improved sanitation and treated water (measured as percentage of the population). Both of these have experienced increases between 5 and 12 percentage points in East Asia and the Pacific, Middle East and North Africa, Latin America and the Caribbean, and South Asia, in the short period of time between 1990 and 2000. These are changes encompassing more than $5 \%$ of the population in the regions in a period of only 10 years. Though data are not available, it is not difficult to imagine that changes along these dimensions must have been very significant between 1960 and 1990 and that these may have played an important role in the mortality reductions in the period. Some casual observations support this view. For example, the extreme outlier in terms of life expectancy in Latin America is also an extreme outlier in terms of access to improved sanitation and treated water (Haiti). In addition, some of the countries in that same region that experienced extremely large life expectancy gains with very little economic growth - such as Bolivia, Honduras, and Nicaragua are precisely countries that had significant improvements in the public provision of these services. This evidence suggests that factors playing a role in the first stages of the US experience were also important in the recent experience of developing countries.

But evidence suggests that some other factors may also have been relevant. These are technologies related to large-scale immunizations, which were not available during the first half of the twentieth century and, therefore, could not have been responsible for the early mortality reductions in developed countries. The first two columns in Table 7 present data on 
immunization rates for DPT and measles between 1980 and 2000, measured as the percentage of children below one year of age receiving the respective vaccine. The extent of changes registered in the table is striking. In this twenty-year period, the average immunization rates in East Asia and the Pacific, Middle East and North Africa, and Latin America and the Caribbean jumped from levels around $40 \%$ to close to $90 \%$. South Asia and Sub-Saharan Africa also presented significant improvements along these dimension, though at a much slower pace than other regions. Even accounting for the bias discussed by Murray et al (2003), these numbers still imply an increase of almost $100 \%$ in immunization rates. In several specific countries, at least one of the immunization rates increased by more than 50 percentage points in this twenty-year interval. As of year 2000, the averages observed in these developing regions were extremely close to the ones observed in the developed world. Again, despite the unavailability of data, it is not difficult to imagine that similar improvements were observed between 1960 and 2000, in which case immunization rates would have changed from arbitrarily low levels in the immediate post-war to close to $90 \%$ by the turn of the century.

The fact that the United Nations Expanded Program on Immunization was established only in 1974 suggests that this view is probably accurate. This program subsidized large scale immunization of several different diseases and transferred immunization technologies to developing countries, leading, among other things, to virtual eradication of poliomyelitis in the Americas. The worldwide immunization rate (children under one) for the six diseases that originally constituted the main target of the program - tuberculosis, diphtheria, neonatal tetanus, whooping cough, poliomyelitis, and measles - is estimated to have risen from 5\% in 1974 to $80 \%$ today. The choice of target diseases itself had the explicit goal of maximizing impact, giving priority to diseases that had a high burden and for which there were well-tried vaccines available at low costs (World Health Organization, 2003, World Bank, 2003). In the case of the Americas, the Pan American Health Organization created the "Revolving Fund for Vaccine Procurement," which subsidized the purchase of vaccines by member countries, leading to savings that, in some circumstances, amounted to $80 \%$ of the price of vaccines (de Quadros et al, 1998).

In the case of immunization, casual observation also suggests that it is a potentially important factor in explaining the mortality reductions observed between 1960 and 2000. Again, the country with an exceptionally poor performance in terms of life expectancy in Latin America 
and the Caribbean (Haiti) is precisely the one that lags way behind the rest of the region in immunization rates. And countries experiencing exceptional gains in life expectancy without significant improvements in income also experienced exceptional increases in immunization rates (for Bolivia, Honduras, and Nicaragua both immunization rates increased by at least 57 percentage points in only 20 years).

These factors are likely to play a particularly important role in the reduction of child mortality. But, in principle, reductions in child mortality may also have other determinants, such as improved nutrition of children and mother. Table 7 shows that this does not seem to be the case. Though malnutrition prevalence (for children under 5) shows some reduction in East Asia and the Pacific, South Asia, and, more moderately, in Latin America and the Caribbean, it increases slightly in the Middle East and North Africa and in Sub-Saharan Africa. During this period, Middle East and North Africa experienced spectacular reductions in child mortality, with the mortality rate under the age of 5 dropping from 252 per 1,000 live births in 1960 to 50 in 2000. The same type of evidence can be seen from the experience of specific countries in other regions. For example, in Nicaragua and Honduras, where mortality under the age of 5 was reduced from around 200 to 40, the prevalence of malnutrition actually increased. Other dimensions directly related to nutrition within the family also do not seem to be particularly relevant during this period. To the extent that these factors end up reflected in the birth weight of the child, the data do not show any consistent improvement. In reality, the percentage of low birth weight babies remained stable or increased slightly in most regions of the world between 1980 and 1995. This probably reflects, to a great extent, improvements in medical sciences in dealing with problematic pregnancies, which end up reflected in a higher percentage of fragile babies surviving birth. But, nevertheless, this implies a compositional change in the pool of children surviving birth that, if anything, would on itself imply increased mortality in the first years of life.

Therefore, the aggregate evidence suggests that, apart from income, two factors are strong candidates for determinants of the life expectancy gains observed in developing countries since World War II. Large-scale immunizations and improved public health infrastructure may have been among the key factors determining the reductions in mortality observed during the last 40 years. We now move to a discussion of the limited statistical evidence available regarding the 
role of these factors, as well as that of technological diffusion, in determining recent changes in mortality.

\subsection{Cross-Country Correlates}

Despite the limitations suggested in section 3, recent econometric attempts to identify the determinants of cross-country mortality changes drew heavily on the trade literature on international diffusion of productive technologies (Keller, 2004). Maybe because of immediate data availability, the majority of econometric studies has focused on the transfer of technology through imports of goods. Jamison et al (2001), Owen and Wu (2004), and Papageorgiou et al (2006) find that imports and, more generally, openness to trade are associated with faster reductions in mortality. All these authors develop arguments along the lines of the literature on diffusion of productive technologies, but they are not always able to deal convincingly with endogeneity and identification issues, and leave open the possibility that trade variables are actually capturing the effects of other policies or unobservable variables. ${ }^{10}$ Owen and $\mathrm{Wu}(2004)$, in particular, find a strong correlation between trade and mortality for developing countries, while the correlation is virtually zero for rich countries. Given the arguments developed in the previous paragraph, it is not clear that this should be the case. They also present some evidence on other important factors: higher rates of immunization (DPT and measles), higher amounts of aid per capita targeted to water improvement, and higher female schooling are all systematically associated with lower mortality.

In respect to the effect of trade itself, Jamison et al (2001) notice that, when the analysis does not control for openness, countries with difficult access to the outside world (landlocked) and countries in tropical areas are found to experience smaller improvements in life expectancy. To the extent that these variables are related to access to trade and to the adaptability of imported technologies for local production of health, this tends to make the results more credible. If trade is indeed capturing the incorporation of technologies produced in developed areas, countries with difficult access to trade or with different environments should benefit less from new technologies.

\footnotetext{
10 “Good governments” may implement good economic and social policies. Good economic policies may lead to openness, while good social policies may lead to reductions in mortality. This would generate a correlation between openness and mortality in the data, even thought there would be no causal relationship between the two variables.
} 
The results related to trade are also somewhat more convincing in the case of Papageorgiou et al (2006), who measure the relevance of imports in a more sophisticated and adequate way. They focus particularly on medical imports originating from the ten countries responsible for the bulk of medical $R \& D$ in the world. In a series of different specifications, they find these imports to be systematically related to lower mortality. They also find that female schooling, caloric intake, and physician availability are significantly correlated with the crosscountry variation in mortality.

The relevance of medical technologies, specifically in what refers to new drugs, is further supported by the evidence discussed in Lichtenberg (2003). In a sample of 50 countries including only upper-middle level developing and developed countries, he shows that the launch of new drugs (new chemical entities) between 1986 and 2000 had a strong positive impact on the probability of survival. He claims that these new drugs were responsible for $40 \%$ of the gains in life expectancy observed in the sample during the period.

Schultz (1993), on his turn, analyzes the role of other types of cross-country determinants of mortality between 1972 and 1988. He finds that caloric consumption and maternal education were the variables most closely related to mortality, with number of physicians, supply of water and sanitation not playing statistically significant roles. The results related to female education are in line with those found by Owen and $\mathrm{Wu}$ (2004), but other results related to public health infrastructure and access to health facilities contradict some of the later evidence. In any case, endogeneity and omitted variables remain open issues in most of the cross-country literature and no study dealt with all of their implications in a convincing way.

As a whole, this evidence indicates that new technologies incorporated in medical goods and medicines do seem to be important in determining gains in life expectancy. But it is likely that these dimensions are relatively less important for poor developing countries, where reductions in mortality have been observed even with very low expenditures directly targeted to health consumption. In this direction, the cross-country evidence offers some very preliminary indication that other factors, such as schooling and provision of public health goods, may also have been relevant. In order to shed further light on the role played by these factors, the next section discusses the micro-level evidence available from developing countries. This evidence also allows us to uncover the role of country specific interventions and community-level 
programs for which aggregate data are not available (such as anti-malaria campaigns and family health programs).

\section{Micro-Evidence from Developing Countries}

There is a large array of demographic literature on within country variations in mortality. Most of this literature concentrates on the analysis of infant and child mortality, for which demographic techniques based on retrospective surveys on number of children ever born and number of children alive give quite accurate estimates. Two major strands of papers can be identified: the first one analyzes the impact of particular interventions, events, or health programs; and the second one looks at correlates of within-country variations in mortality. In this section, we selectively review some results from both strands of literature.

On the evaluation of particular health interventions, Gray (1974) is an early example of analyses of the impact of malaria control measures. Gray (1974) evaluates the contribution of malaria control to the post-war mortality decline observed in Ceylon (current Sri Lanka). Starting in 1945, commercial supplies of DDT became available and a more effective control of malaria in Ceylon started taking place. This led to an elimination of the mortality differential previously existent between endemic and non-endemic areas, and to fast declines in national mortality rates. According to the estimates, malaria control contributed with $23 \%$ of the observed reduction in the crude death rate during the post-war period (up to 1960). In the initial control period (19461950), malaria elimination is estimated to have contributed with roughly $1 / 3$ of the total

mortality decline (particularly relevant for children below age 5 and adults above 45). Gray (1974) also mentions similar results obtained in studies of other malaria control programs (Guyana, Guatemala, Mexico, Venezuela, and Mauritius). Nevertheless, Langford (1996) argues that these numbers are likely to be somewhat overestimated, and suggests that DDT alone was probably responsible for no more than $16 \%$ of the reduction in mortality in the post-war period. He points to the fact that other anti-malarial measures and improvements in public health were observed before the 1940's, and are also likely to have played some role in the reductions in mortality observed immediately after the war.

Lincoln et al (1983), on their turn, analyze the effect of family planning, tetanus vaccine, and oral rehydration therapy. They look at data from sixteen years of operation of the International Centre for Diarrheal Disease Research (Matlab Thana, Bangladesh, between 1966 
and 1981). During this period, there were several changes introduced in the services provided to the target population. In some cases, randomized double-blind trials were also implemented. The results indicate that tetanus vaccine given to pregnant women reduced newborn 4-14 day mortality by 68\% (tetanus was initially an extremely important cause of death among infants, accounting for $26.2 \%$ of deaths). Other therapies also appeared as important in reducing mortality, with a broad program of family planning being responsible for a $25 \%$ reduction in the crude death rate (half the decline in the period), and rehydration therapy for another $9 \%$.

Macinko et al (2006) also present evidence of significant effects of health programs targeted at the family and household level. They use state-level panel data from Brazil (19902002) to evaluate the impact of a family health program on mortality. The program (Programa Saúde da Família) was largely based on preventive care, but evidence shows that family inclusion in the program also affected rates of breastfeeding and immunization, and improved maternal management of diarrhea and respiratory infections. The program was particularly effective in reducing deaths attributable to diarrhea.

From a historical perspective, Díaz-Briquets (1981) discusses the evolution of mortality in Cuba (mainly Havana) between 1899 and 1953, when the country was subject to considerable American influence. Following the Spanish-American war, Cuba was occupied by the US for four years (between 1898 and 1902). After emancipation, the Platt Amendment gave the US right to intervene in Cuba's internal affairs if certain conditions - such as sanitary improvements were not met. US occupation instituted a series of sanitary reforms, leading to virtual elimination of yellow fever from the country (following the first verification of the mosquito theory of transmission), and reductions in mortality from tuberculosis and other infectious and parasitic diseases. Reduction in tuberculosis mortality seems to have been due initially to improvements in economic conditions and nutrition and, after the 1940's, to the introduction of antibiotics. Other infectious and parasitic diseases were more directly affected by specific sanitary and public health measures: diphtheria mortality was reduced by the use antitoxin (freely distributed by national sanitation authorities); malaria due to anti-mosquito campaigns; and diarrhea, gastritis and enteritis due to extensive sanitary reforms in Havana (improved and more abundant water supply and public health efforts to teach proper infant care, accompanied by increases in literacy rates). Mortality by influenza, pneumonia, and bronchitis was reduced only after 1931, and mainly after 1943, so that the reduction must have been partly due to the use of modern drugs 
(there was also a moderate previous decline, due to improvements in living conditions). McGuire and Frankel (2005), though recognizing the importance of education, urbanization and targeted health programs, highlight that improvements along these dimension occurred well before 1945, while a significant part of the progress in life expectancy in Cuba was observed only after that. Therefore, the authors argue that the role of access to health care for an exceptionally large fraction of the population (due to a large supply of doctors, small geographic size of the island and access to services by the urban poor) should not be underestimated.

The role of education, sanitation, and access to water and medical services is also stressed in several within-country papers on child mortality. Haines and Avery (1982) analyze the experience of Costa Rica between 1940 and 1970, and try to disentangle the effects of education, income, sanitation, housing, and medical services. The authors conduct a cross-sectional analysis using census data (between 1968 and 1973) on the cantons of Costa Rica. They find that medical care (proportion of births having medical attention) had a substantial impact on child mortality independently of other variables (alone, accounted for $64 \%$ of the regional variation in infant mortality). From the perspective of changes through time, mother's education, fertility and sanitation appeared as important factors associated with mortality reductions. Overall, development (as related to income per capita, literacy, and caloric consumption) accounted for 50\% of the mortality decline in Costa Rica between 1940 and 1970. McGuire (2001) shows that the trend of mortality declines continued in Costa Rica even after 1970 and argues that factors similar to those highlighted by Haines and Avery (1982) also played an important role in this later experience. Similarly, Haines et al (1983) use national samples of censuses from Guatemala (1959-1973) and conduct analyses on small geographic units (90 aggregations of municipalities) to show that women's education and sanitation were the most important factors determining child mortality differences. Alves and Belluzzo (2004) find that education and sanitation were also the key determinants of changes in child mortality in the case of Brazil, between 1970 and 2000. Their study analyzes Brazilian municipality data over a period when substantial reductions in child mortality took place.

Evidence on the importance of access to clean water, again together with mother's education, is presented by da Vanzo and Habicht (1986), Merrick (1985), and Macinko et al (2006). Using micro data from Malaysia between 1946 and 1975, da Vanzo and Habitch (1986) find that mother's education and piped water were the factors most closely associated with child 
mortality, while sanitation was also marginally relevant. Other social aspect that appears as an important determinant of mortality in the case of Malaysia is breast-feeding, which seemed to reduce the negative effect of lack of access to treated water. Merrick (1985) and Macinko et al (2006) find similar evidence for Brazil. Merrick (1985) uses census and household survey data between 1970 and 1976 to track down the effects of an extensive effort undertaken by the Brazilian government in the early 1970's to improve urban environmental conditions (PLANASA), through better water supply and sanitation. He finds that parents' education and access to piped water were the factors most closely related to child mortality both in 1970 and 1976. Particularly, access to piped water explained about one-fifth of the regional differentials in child mortality. Macinko et al (2006), in their evaluation of the family health program discussed above, also show incidentally that access to water and female literacy were closely related to mortality.

Jain (1985) analyzes data for the period between 1973 and 1978 in rural India, and shows that, together with mother's literacy, type of birth attendant and triple vaccination were closely related to regional variations in child mortality. Breaking down child mortality in different periods of the child's life, the author shows that poverty and medical care received at birth were particularly important for neo-natal mortality, while availability of medical facilities in the village and the extent of triple vaccination during infancy were most important for post-neo-natal mortality.

In terms of within country studies, Caldwell (1986) takes a broader perspective and discusses several dimensions of economic, social, or public health changes that may have affected what he calls "breakthrough periods" of mortality reductions. He analyzes three historical experiences of exceptional declines in mortality - Kerala (India, 1956-1966), Sri Lanka (1946-1953), and Costa Rica (1970-1980) - and argues that these three experiences were also exceptional in their social and political environments, and in their effectiveness in providing inputs in the areas of education, health services, and nutrition. He particularly highlights the role of cultural factors - female autonomy, intrinsic value attached to education, open political system (competition), large civil society without rigid class structure, and national consensus related to policies - as important in allowing for the adoption of new health inputs and the absorption of new technologies. In this interpretation, education and a demanding public appear 
as key factors in order for interventions to be implemented and to work. Also, as other evidence has shown, results did not depend on the use of particularly expensive technologies.

In the case of Sri Lanka, cholera was contained starting in the 1870's through quarantine measures (for arrivals from India) and later construction of a pipe water system, while neonatal tetanus was cut down by the systematic use of midwives. Starting in 1910, successful campaigns against diarrhea, respiratory infections, and hookworm disease (supported by the Rockefeller Foundation) stressed the need for public health, sanitation, and personal hygiene. Other important events included the malaria campaign started immediately after the war (led to nearly eradication at the time through the use of DDT spraying) and the popularization of penicillin and sulfa drugs. Health expenditures over this period never rose above 1.5\% of GDP, despite a profound enhancement in public health infrastructure and programs (Caldwell, 1986).

In the Indian state of Kerala, the mortality breakthrough took place between 1956 and 1966. During this period, deaths from cholera and smallpox, which accounted for one-sixth of all deaths at the end of the $19^{\text {th }}$ century, were drastically reduced. After World War I, these causes of death never again accounted for more than $3 \%$ of all deaths. In this experience, extensions of public health programs and immunization - through provision of community level services seem to have been the immediate cause for most of the mortality reductions. Similarly, Costa Rica increased expenditure on health services leading to a breakthrough period between 1970 and 1980. As in Kerala, easy-access and community level services - coupled with immunization campaigns - were very important in reducing infant and child mortality (Caldwell, 1986).

Riley (2005b) describes the experience of exceptional mortality reductions of Jamaica (life expectancy at birth above 75 years in 2000), and compares it to the three cases analyzed by Caldwell (1986). He argues that in Jamaica, as in Kerala, Sri Lanka, and Costa Rica, women have historically been more independent (though for different reasons), public schooling developed early, and there was a tradition of open and lively discussion of political and social issues. But, on the other hand, widespread corruption and organized crime have greatly undermined the institutional effect of political freedom. Also in Jamaica, substantial government investments in health and widespread use of the schooling system as a means of delivering public health education to the population - both dating back to British colonial times - seem to have been particularly important. School teachers were explicitly trained to be health educators, teaching people how to recognize and treat themselves against specific diseases and vectors. 
Riley (2005b) concludes that reductions in mortality in Jamaica up to the end of the $20^{\text {th }}$ century were driven mostly by improvements in public health, individual behavior, and schooling.

It is clear from the discussion in previous paragraphs that the evidence from within country mortality studies is very diverse in nature, focus, and methodology. Nevertheless, it does address some concerns raised in the demographic literature, and also reveals some surprisingly consistent results.

First, evidence shows that interventions targeted at a particular set of diseases (be it malaria, tetanus, or diarrhea, for which there are 12 possible agents) have shown substantial and sustained success in reducing mortality. Therefore, concerns related to the possibility that narrow approaches focused on specific technologies end up simply increasing mortality from competing causes of death do not seem to be empirically relevant (Mosley, 1984 and Hill and Pebley, 1989). In reality, Hill and Pebley (1989) discuss evidence from malaria and measles eradication programs in Guyana, Kenya, Sri Lanka, Tanzania, and Zaire that suggests exactly the opposite: in the implementation of targeted programs, overall reductions in mortality seem to be systematically larger than the direct reduction in the cause-specific mortality that constitutes the initial target. There seems to be synergistic benefits from reductions in mortality from one cause of death that end up reducing mortality also from other causes. This would be the case if, for example, one type of disease increased an individual's probability of dying from another disease (due to weakened immune system or reduced capacity to absorb nutrients, as suggested by Mosley, 1984). Still, the evidence does support the idea that family health programs, implemented at the community level and taking into account the broader scope of social specificities facing the target population, can also be very effective in reducing mortality. This was the case with successful programs implemented in Bangladesh and Brazil, and also with some dimensions of the Jamaican experience. So, in general, there is no need for an a priori choice between disease-specific targeted interventions and broad interventions focused on health practices and the cultural context within the community or family. Evidence indicates that both strategies are potentially effective in reducing mortality. The ideal program in each particular case seems to be a function of the extent of mortality from endemic conditions for which specific interventions are available, as compared to the extent of mortality from causes that can be minimized through improvements in individual or collective health practices. 
Second, in relation to the specific role played by different factors, there is an overwhelming amount of suggestive evidence pointing to the importance of education, particularly mother's education, in determining infant and child mortality. Part of the association between these variables reflects the effect of income on health, but studies controlling for socioeconomic status still found robust correlations between mother's education and child mortality. This relation, even if taken as a causal one, is not yet fully understood in the literature. Haines and Avery (1982) and Haines et al (1983) hypothesize that better educated mothers may seek medical care more actively, may be more aware of sanitary precautions, nutritional information, and health services, and may be better able to recognize serious child health conditions. Jain (1985) presents evidence in support of this view, showing that mother's literacy improves the type of medical care used during birth and the use of preventive and curative measures during the post-neo-natal period. Nevertheless, other authors view the effect of schooling as being one of modernization and indoctrination of the target population (Caldwell, 1986 and Riley, 2005b). According to this interpretation, schooling would familiarize the population with Western values and institutions, reducing their resistance to seeking medical attention or using modern medicines. Hobcraft (1993) reviews a vast array of evidence on the effect and the channels through which maternal education affects child mortality. He shows that educated mothers are better informed about and more likely to use medical facilities and other health technologies, are more likely to have their children immunized and to have received prenatal care, and are more likely to have their deliveries attended by trained personnel. At the same time, Hobcraft (1993) identifies some social aspects that may also intervene in the relation between maternal education and child mortality: educated mothers marry later and have fewer children, therefore tending to emphasize quality rather than quantity of children. Overall he identifies five channels linking mother's education to child mortality, but is unable to quantify the relative importance of each one. These channels would include greater cleanliness among more educated women, increased utilization of health services, greater emphasis on child quality, and enhanced female empowerment (including an increased feeling of control over the outside world, more identification with modern institutions, greater individual confidence, and increased bargaining power within the family).

The potential role of access to clean water and sanitation suggested by the aggregate data is also partially supported by the micro evidence. Different micro-studies tended to emphasize 
one of these dimensions and, maybe due to a high degree of correlation between the two, have rarely been able to identify independent effects of both. But various papers cited here identify a significant correlation between either sanitation (Haines and Avery, 1982, Haines et al, 1983, and Alves and Belluzzo, 2004), or access to clean water (da Vanzo and Habicht, 1986, Merrick, 1985, and Macinko et al, 2006), and mortality. Also, anecdotal evidence from Cuba and Kerala, among others, confirms the potential importance of factors linked to infrastructure in triggering successful experiences of mortality reduction.

Overall, the evidence supports the effectiveness of specific interventions - such as malaria control programs, rehydration therapy, and immunization - in reducing mortality. It also indicates that family and educational health programs can improve individual and community level practices, reducing the probability of infections and improving health management. Finally, it highlights the importance of health infrastructure, through access to clean water and sanitation. Given the diverse methodological nature of the studies discussed, it is impossible, based solely on this evidence, to isolate the specific role of each different factor.

\section{Conclusion: Understanding Mortality Changes across and within Countries}

Bringing together the evidence on the evolution of life expectancy across countries and on the changes and correlates of mortality within countries can help us understand the determinants of mortality improvements and their implications for the evolution of health inequality. If we think about the recent process of global health improvement as one of discoveries, diffusion, and absorption of new ideas, technologies, and practices, this process will be mirrored by changes in the distribution of health outcomes across and within countries, according to the nature of the new technologies and their gradual transmission throughout the world.

Studies based on micro data, by revealing the within country pattern of mortality inequality and its evolution through time, shed light on the nature of the technological changes driving the reduction in mortality. In this respect, Haines et al (1983) notice that mortality differentials (urban-rural, by educational level, etc) increased in Guatemala while mortality was reduced. In addition, the interaction of different dimensions seemed to enhance inequality, so that educational level tended to be more advantageous in the capital than elsewhere. Along the same lines, da Vanzo and Habitch (1986) found that the effect of mother's education on child 
mortality in Malaysia was increasing through time, while water and sanitation became less important. They also found evidence that the effect of mother's education was particularly strong in more developed areas.

Historical evidence from the US also suggests that the educational gradient of mortality has increased through time (Preston and Haines, 1991). In the end of the $19^{\text {th }}$ century, just before the germ theory of disease became widely accepted and applied, mortality differentials in the US across occupations or social classes were rather small. Professional and literate people had a minor advantage when compared to the rest of the population, and even children of doctors faced mortality rates that were only 6\% below the national average. Already by 1925, children of teachers and doctors had mortality rates corresponding to only $65 \%$ of that from the average population, suggesting that progress and scientific knowledge tended to increase health inequalities along educational lines. Similarly, countries today at a development level comparable to that of the US in 1900 typically have higher life expectancies and steeper mortality-educational gradients than the US did at that time.

But results related to the effect of development on health inequality are not consensual in the literature. Haines and Avery (1982), for example, find that education and urban residence were associated with lower mortality in Costa Rica, but that the educational gradient was higher in rural than urban areas, and that the urban mortality advantage disappeared for high levels of education. Similarly, they also find that the response of mortality to education was higher among women with low education, and tended to disappear as educational level increased. Merrick (1985) also finds similar evidence for Brazil. He shows that improved and increased water supply attenuated mortality differentials associated with education and income (effect of water stronger among low income groups). Macinko et al (2006), also for the case of Brazil, show that access to water and female literacy were particularly important determinants of mortality in the poorer regions of the country (North and Northeast), and that the effect of family health programs tended to be 3 times larger in these same regions.

Still, there is a large amount of evidence indicating that within country mortality inequality may increase as average mortality is reduced. For the US, UK, and Western Europe, evidence suggests that health inequalities increased in recent years (Glied and Lleras-Muney, 2003). For developing countries, in addition to the cases of Guatemala and Malaysia mentioned above, Minujin and Delamonica (2004) look at Demographic and Health Surveys from 18 
developing countries and show that inequality in under-five mortality seems to have increased during the 1990’s in at least 8 of them (Bangladesh, Colombia, Dominican Republic, Indonesia, Kazakhstan, Philippines, Uganda, and Zimbabwe).

Caldwell (1986) already hypothesized that development and technology might increase the educational gradient of mortality, but his argument - as well as that of more recent authors seems to hinge on an implicit assumption about the nature of the technology being considered. Technologies related to individual-level inputs used in the production of health seem to be subject to the effectiveness with which individuals can use the inputs. Evidence indicates that more educated individuals have higher survival advantage in diseases for which medical progress has been particularly important, and that this advantage is greater for recent technologies (Glied and Lleras-Muney, 2003). More educated individuals are also more likely to use recently developed drugs, above all in situations where individuals repeatedly purchase the same drug, suggesting that education increases the capacity of individuals to learn from experience (LlerasMuney and Lichtenberg, 2002). Studies on the AIDS epidemic in Africa (Burkina Faso, Cameroon, Ghana, Kenya, Tanzania, and Uganda) suggest that schooling is closely related to the adoption of protective behaviors, such as use of condom, counseling and testing, and discussion among spouses; it also suggests that educated individuals are more responsive to information campaigns (de Walque, 2004 and 2006). Similar evidence on the role of maternal education in determining child mortality was discussed in the last section (see, for example, Hobcraft, 1993). New technologies associated with individual actions can therefore offer an advantage to the more educated, if they are better able to comprehend and adopt the technology. In these cases, diffusion of new technologies might increase mortality inequality within countries.

But, on the other hand, technology adoption is sometimes also incorporated in public goods. In these cases, provision of a new technology may affect individual outcomes independently of individual actions (such as with clean air and water), and may in reality reduce the relevance of personal behavior in determining health status. The evidence presented on malaria control in Ceylon, family health programs in Brazil, and access to urban public health infrastructure in Costa Rica, Malaysia, and Brazil indicates that all these "technologies" seem to reduce the importance of individual behavior - and, therefore, individual characteristics - in determining health outcomes. In these cases, one would expect introduction of new technologies to be associated with reduced health inequality within countries. 
Therefore, contrary to the case of cross-country mortality, it is difficult to state unequivocally what the effect of recent technological diffusion on within-country inequality has been. Based on the evidence discussed before, the impact of technology adoption on withincountry health inequality seems to depend on two dimensions: the character of the technology (private versus public) and its degree of diffusion. Diffusion of new private technologies whose use is still restricted to relatively small portions of the population are likely to lead to increasing inequality, as relatively more educated and well-off people benefit more from it. With time, as the private technology's use becomes widespread throughout the population, inequality in health would then start being reduced. This sequence of events would mimic the process of international diffusion of medical technologies across countries, and reproduce its impact on the evolution of inequality.

With public technologies, however, as long as all the population of a certain area can benefit from the public good, the effect should be in the direction of reducing mortality irrespective of individual characteristics, and maybe in some cases even reducing the effect of specific individual traits (such as education) on mortality. Still, in reality, adoption of public good technologies also varies within a country - across neighborhoods, cities, and states - and the timing of adoption may well depend on the political influence and organization of different groups. In this case, the effect of introduction of new technologies on inequality would also depend on its degree of penetration and on the level of analysis in question. Though introduction of clean water distribution systems may reduce health inequality between the wealthy and poor within a single city, it may increase inequality across different cities in the same country, as long as cities benefiting from the new system are initially better off. Across different levels of aggregation - from countries, through states and municipalities, to individuals - differential changes in inequality actually reveal the process of technological diffusion itself, and the nature of the technology being absorbed.

The long term evolution of life expectancy inequality across countries is also intimately linked to this same pattern of technological innovation and diffusion. Despite the almost monotonic post-war trend towards reduced inequality, history has not always been the same. Bourguignon and Morrison (2002), for example, show that life expectancy inequality across countries increased consistently between 1820 and 1930, when then it started falling. Vallin and Meslé (2004) restrict the analysis to a group of 9 developed countries and show that, among 
these countries, life expectancy inequality increased steadily between mid $18^{\text {th }}$ century and the turn of the $20^{\text {th }}$ century, when it also started falling to reach its lowest level in recent years.

In line with the arguments developed above, Vallin and Meslé (2004) suggest that the idea of an epidemiological transition, characterized by a fixed sequence of events, is not the adequate concept to understand the improvements in life expectancy observed across-countries in the last two hundred years. They suggest that the pattern of evolution of life expectancy across countries, and therefore the evolution of life expectancy inequality, is driven by new knowledge and by the gradual process of absorption of this new knowledge by different societies. Typically, as new knowledge emerges and some countries take advantage of the technologies implied by it, health inequality would increase reflecting the differential access to the new benefits across countries. If the technology became accessible to a large number of countries, its subsequent widespread diffusion would eventually lead to reduced inequality. Absorption capacity across different countries would then depend on the nature of the technology itself, and on institutional aspects of the country, as related to its infrastructure, provision of health public goods, and political responsiveness.

This is a paradigm based on the dynamics of technological shocks and their international diffusion, which would have speed and penetration dependent on the specific type of technology and on the characteristics of the different countries. Vallin and Meslé (2004) call it a "health transition," as opposed to the term "epidemiological transition” made famous by Omran (1971). They identify three such technological shocks that marked the dynamics of health inequality throughout the $20^{\text {th }}$ century: the conquest of mortality from infectious diseases, which was characterized as an epidemiological transition by Omran (1971) and is still diffusing throughout the developing world; the cardiovascular revolution, which started in the mid 1960's and is still mostly restricted to the developed world; and a potential progress against mortality at very old ages taking place right now and benefiting only a handful of countries. Associated with each one of these breakthroughs there would be an initial period of increasing inequality, as only few leading countries took advantage of the initial progress. Following, if the technology spread through other parts of the world, there could be a reduction in inequality. This sequence of events is close to completion in what refers to infectious diseases, where the initial increase in international health inequality in the $19^{\text {th }}$ century was followed by a reduction in inequality starting in the mid $20^{\text {th }}$ century. With cardiovascular diseases, we would still be observing a 
period of increasing international inequality, as shown by the evidence presented in Becker et al (2005) and the discussion in Vallin and Meslé (2004). Finally, regarding the fight against aging, this process would still be at its initial stages, with very few leading countries taking advantage of the new technologies (Vallin and Meslé, 2004).

Based on the evidence discussed above, the consequence of these waves of technological diffusion to mortality reductions and inequality within countries would depend on the nature of the technologies and on the within country pattern of geographical diffusion. But it is not difficult to imagine that patterns similar to those observed across countries would emerge across different regions of the same country, as more developed areas were better able to initially take advantage of certain types of technological improvements. At the same time, broad health projects - taking place at the national scale - would probably lead to more homogenous reductions in mortality and to instantaneous reductions in overall health inequality (national immunization or anti-malaria campaigns, for example). Still, the recent waves of technological advance - related to cardiovascular diseases and aging - seem to be more closely related to private health technologies than the breakthroughs in the fight against infectious diseases. Reductions in mortality from cardiovascular diseases require radical changes in personal behavior and expensive medical interventions. These seem to have, in nature, much less of public goods than do some of the early technologies associated with reductions in mortality from infectious diseases (provision of clean water and sanitation, immunization campaigns, antimalaria campaigns, and even provision of basic education). Therefore, one may wonder that, once the conquest of mortality from infectious diseases is complete in most of the developing world, diffusion of the second and third waves of the health transition will be accompanied by a long period of rising life expectancy inequality, both within and across countries. 


\section{References}

Alves, Denisard and Walter Beluzzo (2004). Infant mortality and child health in Brazil. Economics and Human Biology, v2, n3 (December), 391-410.

Barro, Robert J. and Xavier Sala-i-Martin (1995). Economic Growth. New York, McGraw-Hill, Inc.

Becker, Gary S., Tomas J. Philipson, and Rodrigo R. Soares (2005). The quantity and quality of life and the evolution of world inequality. American Economic Review, v95, n1 (March 2005), 277-91.

Bourguignon, François and Christian Morrisson (2002). Inequality Among World Citizens: 1820-1992. American Economic Review, v.92, n4 (September 2002), 727-44.

Brass, William (1975). Methods for Estimating Fertility and Mortality from Limited and Defective Data. Chapel Hill, Carolina Population Center.

Bruntland, Gro Harlem, Julio Frenk, and Christopher J. L. Murray (2003). WHO assessment of health systems performance. The Lancet, v361, June 21, 2155.

Burström, Kristina, Magnus Johannesson, and Finn Diderichsen (2003). The value of the change in health in Sweden 1980/81 to 1996/97. Health Economics, vol. 12, i.8 (August 2003), 63754.

Caldwell, John C. (1986). Routes to low mortality in poor countries. Population and Development Review, v12, n2, 171-220.

Chen, Lincoln C. Chen, Makhlisur Rahman, Stan D'Souza, J. Chakraborty, and A. M. Sardar (1983). Mortality impact of an MCH-FP program in Matlab, Bangladesh. Studies in Family Planning, v14, n8/9, 199-209.

Cutler, David, Angus Deaton and Adriana Lleras-Muney (2006). The determinants of mortality. Journal of Economic Perspectives, forthcoming.

Cutler, David and Ellen Meara (2001). "Changes in the Age Distribution of Mortality over the $20^{\text {th }}$ Century.” NBER Working Paper 8556.

Cutler, David and Grant Miller (2005). The role of public health improvements in health advances: The twentieth century United States. Demography, v42, n1 (February 2005), 1-22.

Cutler, David and Elizabeth Richardson (1997). Measuring the health of the U.S. population. Brookings Paper on Economic Activity: Microeconomics, 1997, $217-71$.

da Vanzo, Julie and Jean-Pierre Habicht (1986). Infant mortality decline in Malaysia, 1946-1975: The roles of changes in variables and changes in the structure of relationships. Demography, v23, n2, 143-160.

de la Fuente, Angel (1997). The empirics of growth and convergence: A selective review. Journal of Economic Dynamics and Control, 21 (1997), 23-73.

de Quadros, Ciro C. A., Jean Marc Olivé, Cristina Nogueira, Peter Carrasco, and Cláudio Silveira (1998). Expanded Program on Immunization. In: Yehuda Benguigui, Sandra Land, José María Paganini, and João Yunes (eds.). Maternal and Child Health Activities at the 
Local Level: Toward the Goals of the World Summit for Children. Pan American Health Organization, Washington DC, 1998, 141-70.

de Walque, Damien (2004). "How does the Impact of an HIV/AIDS Information Campaign Vary with Educational Attainment? Evidence from Rural Uganda.” World Bank Working Paper 3289.

de Walque, Damien (2006). "The Determinants of HIV Infection and Sexual Behaviors in Burkina Faso, Cameroon, Ghana, Kenya And Tanzania.” World Bank Working Paper 3844.

Deaton, Angus (2004). Health in an age of globalization. In: Susan Margaret Collins and Carol Graham (eds.). Brookings Trade Forum 2004. Brookings Institution Press, Washington DC, 83-110.

Diaz-Briquets, S. (1981). Determinants of mortality transition in developing countries before and after the Second World War: Some evidence from Cuba. Population Studies, v35, n3, 399411.

Easterlin, Richard A. (1996). Growth Triumphant. University of Michigan Press, Ann Arbor.

Easterlin, Richard A. (1999). How beneficent is the market? A look at the modern history of mortality. European Review of Economic History, v3, n3 (December 1999).

Ezzati, Majid, Stephen V. Hoorn, Anthony Rodgers, Alan D. Lopez, Colin D. Mathers, Christopher J. L. Murray, and the Comparative Risk Assessment Collaborating Group (2003). Estimates of global and regional potential health gains from reducing multiple major risk factors. The Lancet, v362, July 26, 271-280.

Fogel, Robert W. (1994). Economic growth, population theory, and physiology: The bearing of long-term processes on the making of economic policy. American Economic Review, v84, n3 (June 1994): 369-95.

Fogel, Robert W. (2004). The Escape from Hunger and Premature Death, 1700-2100 - Europe, America, and the third World. Cambridge, Cambridge University Press, 2004, 191p.

Goesling, Brian and Glenn Firebaugh (2004). The trend in international health inequality. Population and Development Review, v.30, n.1 (March 2004), 131-46.

Gray, R.H. (1974). The decline of mortality in Ceylon and the demographic effects of malaria control. Population Studies, v28, n2, 205-229.

Glied, Sherry and Adriana Lleras-Muney (2003). "Health Inequality, Education and Medical Innovation.” Unpublished Manuscript, Princeton University.

Haines, Michael R. and Roger C. Avery (1982). Differential infant and child mortality in Costa Rica: 1968-1973. Population Studies, v36, n1, 31-43.

Haines, Michael R., Roger C. Avery, and Michael A. Strong (1983). Differentials in infant and child mortality and their change over time: Guatemala, 1959-1973. Demography, v20, n4, 607-621.

Heuveline, Patrick (2001). Demographic pressure, economic development, and social engineering: An assessment of fertility declines in the second half of the twentieth century. Population Research and Policy Review, 20, 365-96. 
Hill, Kenneth and Anne R. Pebley (1989). Child mortality in the developing world. Population and Development Review, v15, n4, 657-687.

Hobcraft, John (1993). Women's education, child welfare and child survival: a review of the evidence. Health Transition Review, v3, n2, 159-173.

Jain, A. K. (1985). Determinants of regional variations in infant mortality in rural India. Population Studies, v39, n3, 407-424.

Jamison, Dean T., Martin Sandbu, and Jia Wang (2001). "Cross-country Variation in Mortality Decline, 1962-87: The Role of Country-specific Technical Progress.” CMH Working Paper Series, Paper No. WG1:4.

Keller, Wolfgang (2004). International technology diffusion. Journal of Economic Literature, v.XXLII (September 2004): 752-82.

Kenny, Charles (2005). Why are we worried about income? Nearly everything that matters is converging. World Development, v33, n1 (January 2005) 1-19.

Keyfitz, Nathan, and Wilhelm Flieger (1968). World Population - An Analysis of Vital Data. Chicago, University of Chicago Press, 1968.

Langford, C.M. (1996). Reasons for the decline in mortality in Sri Lanka immediately after the Second World War: a re-examination of the evidence. Health Transition Review, v6, n1, 3-23.

Lleras-Muney, Adriana and Frank R. Lichtenberg (2002). "The Effect Of Education On Medical Technology Adoption: Are The More Educated More Likely To Use New Drugs?” Unpublished Manuscript, Princeton University.

Lichtenberg, Frank R. (2003). “The Impact of New Drug Launches on Longevity: Evidence from Longitudinal, Disease-level Data from 52 Countries, 1982-2001.” NBER Working Paper 9754.

Livi-Bacci, Massimo (2001). A Concise History of World Population. Malden, Blackwell Publishers, 2001, $3^{\text {rd }}$ edition, 251p.

Macinko, James, Frederico Guanais, Maria de Fátima Marinho de Souza (2006). Evaluation of the impact of Family Health Program on infant mortality in Brazil, 1990-2002. Journal of Epidemiology and Community Health, v60, 13-19.

Mathers, Colin D., Christopher J. L. Murray, Majid Ezzati, Emmanuela Gakidou, Joshua A. Salomon, and Claudia Stein (2003a). Population health metrics: crucial inputs to the development of the evidence for health policy. Population Health Metrics, v1, n6.

Mathers, Colin D., Joshua A. Salomon, and Christopher J. L. Murray (2003b). Infant mortality is not and adequate summary measure of population health. Journal of Epidemiology and Community Health, v57, 319.

Maddison, Angus (2004). "World Development and Outlook 1820-2030: A Quantitative Perspective.” Working Paper, Meeting of OECD Economics \& Environment Directorates, June 2004.

Mankiw, Gregory, Paul Romer, and David N. Weil (1992). A contribution to the empirics of growth. Quarterly Journal of Economics, v107, 1992, 407-37. 
McGuire, James W. (2001). Social policy and mortality decline in East Asia ad Latin America. World Development, v29, n10, 1673-1697.

McGuire, James W. and Laura B. Frankel (2005). Mortality decline in Cuba, 1900-1959: patterns, comparisons, and causes. Latin America Research Review, v40, n2, 83-116.

McKeown, Thomas (1976). The Modern Rise of Population. Academic Press, New York.

McKeown, Thomas and R. G. Record (1962). Reasons for the decline of mortality in England and Wales during the nineteenth century. Population Studies, v16, n2, 94-122.

Merrick, Thomas W. (1985). The effect of piped water on early childhood mortality in urban Brazil, 1970 to 1976. Demography, v22, n1, 1-24.

Minujin, Alberto and Enrique Delamonica (2004). Socioeconomic inequalities in mortality and health in the developing world. Demographic Research, Special Collection 2, article 13, 331354.

Mokyr, Joel (1998). Induced technical innovation and medical history: an evolutionary approach. Journal of Evolutionary Economics, v8, n1, 119-137.

Mokyr, Joel (2000). Why “more work for mother?” Knowledge and household behavior, 18701945. Journal of Economic History, v60, n1, 1-41.

Mosley, W. Henry (1984). Child survival: research and policy. Population and Development Review, v10, Supplement (Child Survival: Strategies for Research), 3-23.

Murphy, Kevin M. and Robert Topel (2003). The economic value of medical research. In: Kevin M. Murphy and Robert H. Topel (eds). Measuring the Gains from Medical Research: An Economic Approach. The University of Chicago Press, 2003, 41-73.

Murray, Christopher J. L., Bakhuti Shengelia, Neeru Gupts, Saba Moussavi, Ajay Tandon, and Michel Thieren (2003). Validity of reported vaccination coverage in 45 countries. The Lancet, v362, September 27, 1022-1027.

Musgrove, Philip (2003). Judging health systems: reflections on WHO's methods. The Lancet, v361, 1817-1820.

Neumayer, Eric (2003). Beyond income: convergence in living standards, big time. Structural Change and Economic Dynamics, v.14, i.3 (September 2003) 275-96.

Nordhaus, William D. (2003). The health of nations: The contribution of improved health to living standards. In: Kevin M. Murphy and Robert H. Topel (eds). Measuring the Gains from Medical Research: An Economic Approach. Chicago, The University of Chicago Press, 2003, 9-40.

Omran, Abdel (1971). The epidemiological transition: A theory of the epidemiology of population change. Milbank Memorial Fund Quarterly, v49, 509-538.

Owen, Ann L. and Stephen Wu (2004). “Is Trade Good for Your Health?” Hamilton College, unpublished manuscript.

Palloni, Alberto (1981). Mortality in Latin America: Emerging patterns. Population and Development Review, v7, n4 (December 1981), 623-49. 
Palloni, Alberto and Kenneth Hill (1997). The effect of economic changes on mortality by age and cause: Latin America, 1950-90. In: Georges Tapinos, Andrew Mason, and Jorge Bravo (eds). Demographic Responses to Economic Adjustment in Latin America. Oxford University Press, Oxford, 75-128.

Palloni, Alberto and R. Wyrick (1981). Mortality decline in Latin America: Changes in the structure of causes of death, 1950-1975. Social Biology, v28, n3-4 (Fall-Winter 1981), 187216.

Papageorgiou, Chris, Andreas Savvides, and Marios Zachariadis (2006). "International Medical R\&D Spillovers.” Journal of International Economics, forthcoming.

Parente, Stephen L. and Edward C. Prescott (1993). Changes in the wealth of nations. Federal Reserve Bank of Minneapolis Quarterly Review, Spring 1993, 3-14.

Philipson, Tomas J. and Rodrigo R. Soares (2005). The economic cost of AIDS in Sub-Saharan Africa: A reassessment. In: Guillem López-Casasnovas, Berta Rivera, and Luis Currais (editors). Health and Economic Growth: Findings and Policy Implications. Cambridge, MIT Press, 2005, 313-336.

Preston, Samuel H. (1975). The changing relation between mortality and level of economic development. Population Studies, v29, Issue 2 (July 1975), 231-48.

Preston, Samuel H. (1980). Causes and consequences of mortality declines in less developed countries during the twentieth century. In: Richard S. Easterlin (editor): Population and Economic Change in Developing Countries. National Bureau of Economic Research, The University of Chicago Press, Chicago, 1980, 289-341.

Preston, Samuel H. (1996). Population studies of mortality. Population Studies, v50, n3, 525-36.

Preston, Samuel H. and Michael R. Haines (1991). Fatal Years - Child Mortality in Late Nineteenth-Century America. Princeton University Press, Princeton.

Quah, Danny T. (1996). Empirics for economic growth and convergence. European Economic Review, v40, 1353-75.

Ram, Rati (2005). Cross-country convergence in income and divergence in life expectancy: A study in reversals and contrasts during the 1990s. Economia Internazionale, v58, n1, 43-50.

Ram, Rati (2006). State of the "life span revolution" between 1980 and 2000. Journal of Development Economics, forthcoming.

Ram, Rati and Theodore W. Schultz (1979). Life span, health, savings, and productivity. Economic Development and Cultural Change, v27, n3 (April 1979): 399-421.

Riley, James C. (2001). Rising Life Expectancy - A Global History. Cambridge University Press, Cambridge, UK.

Riley, James C. (2005a). The timing and pace of health transitions around the world. Population and Development Review, v31, n4, 741-764.

Riley, James C. (2005b). Poverty and Life Expectancy. Cambridge University Press, Cambridge, 2005. 
Ruzicka, Lado T. and Harald Hansluwka (1982). Mortality transition in South and East Asia: Technology confronts poverty. Population and Development Review, v8, n3 (September 1982): 567-88.

Sala-i-Martin, Xavier (2002). "The world distribution of income (estimated from individual country distributions).” NBER Working Paper w8933, May 2002.

Sap, Randa and Stephen C. Smith (2002). Human capital convergence: A joint estimation approach. IMF Staff Papers, v.49, n.2, p.200-11.

Schultz, T. Paul (1993). Mortality decline in the low-income world: Causes and consequences. American Economic Review, v83, n2 (Papers and Proceedings of the Hundred and Fifth Annual Meeting of the American Economic Association), 337-342.

United Nation (1983). Manual X - Indirect Techniques for Demographic Estimation. United Nations, New York.

United Nations (2005). Population and Vital Statistics Report 2004. United Nations, New York.

Vacher, Leon-Clery (1979). A nineteenth century assessment of causes of European mortality decline. Population and Development Review, v5, n1 (March 1979): 163-70.

Vallin, Jacques and France Meslé (2004). Convergences and divergences in mortality: A new approach to health transition. Demographic Research, Special Collection 2, article 2, 11-43.

Younger, Stephen (2001). "Cross-country determinants of declines in infant mortality: A growth regression approach.” Unpublished Manuscript, Cornell University.

World Bank (2003). "Expanded Programme on Immunization Overview." Unpublished Manuscript, World Bank, Washington DC (Downloaded on 12/18/2003 from wbln0018.wordbank.org/HDNet/HDdocs.nsf).

World Bank (2005). World Development Indicators 2004. World Bank, Washington DC.

World Health Organization (2003). "The History of Vaccination.” Unpublished Manuscript, World Health Organization (Downloaded on 12/18/2003 from www.who.int/vaccinesdiseases/history/history.shtml). 
Figure 1: The Changing Relationship between Income and Life Expectancy; 1960, 1990, and 2000

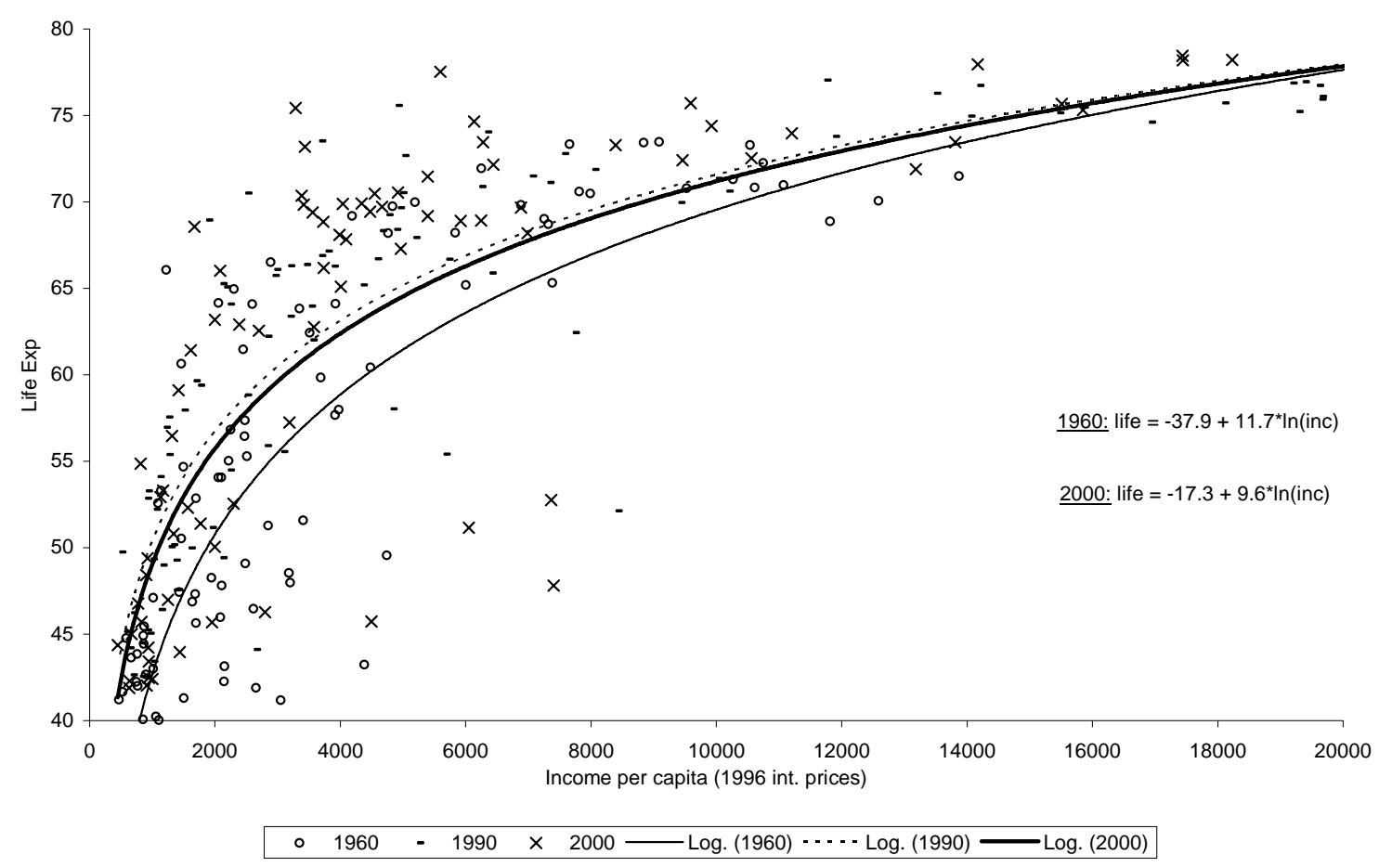

Figure 2: Cross-Country Regression to Mean in Life Expectancy, 1960-2000

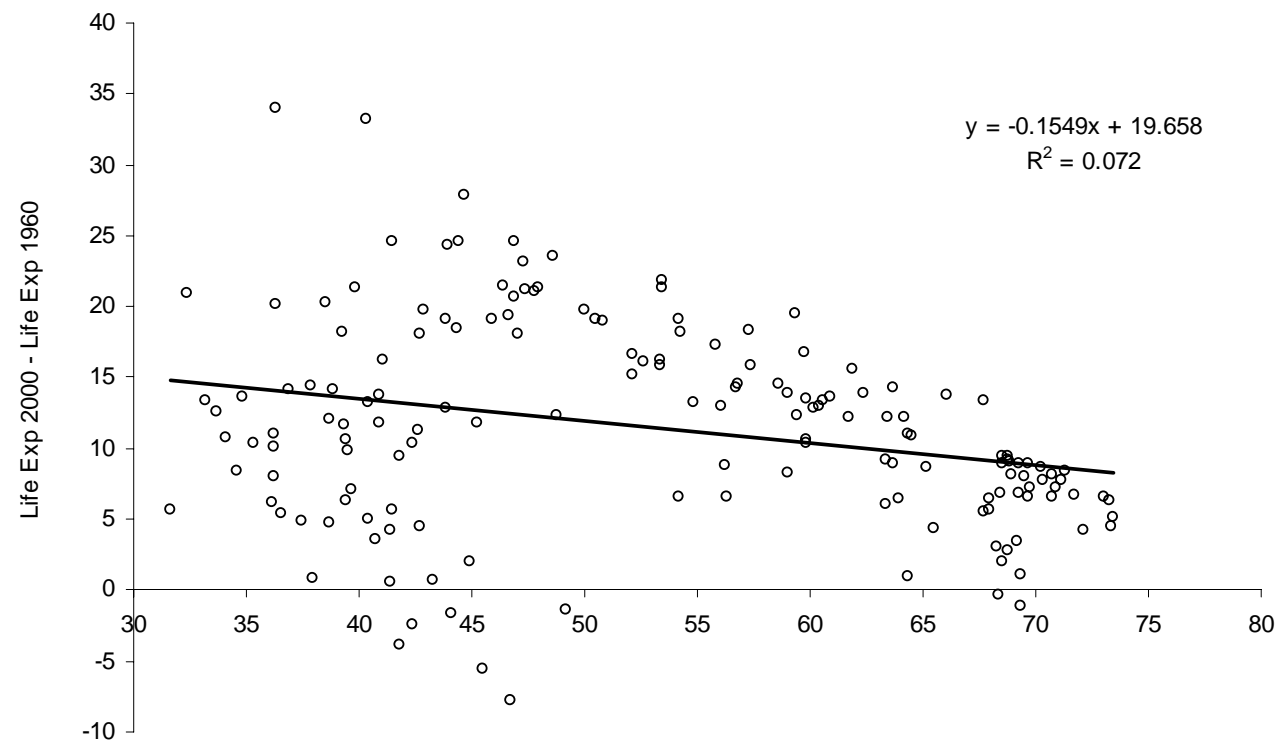

Life Exp 1960 
Figure 3: Cross-Country Regression to the Mean in Life Expectancy, 1960-1990 and 19902000

(a) $1960-1990$

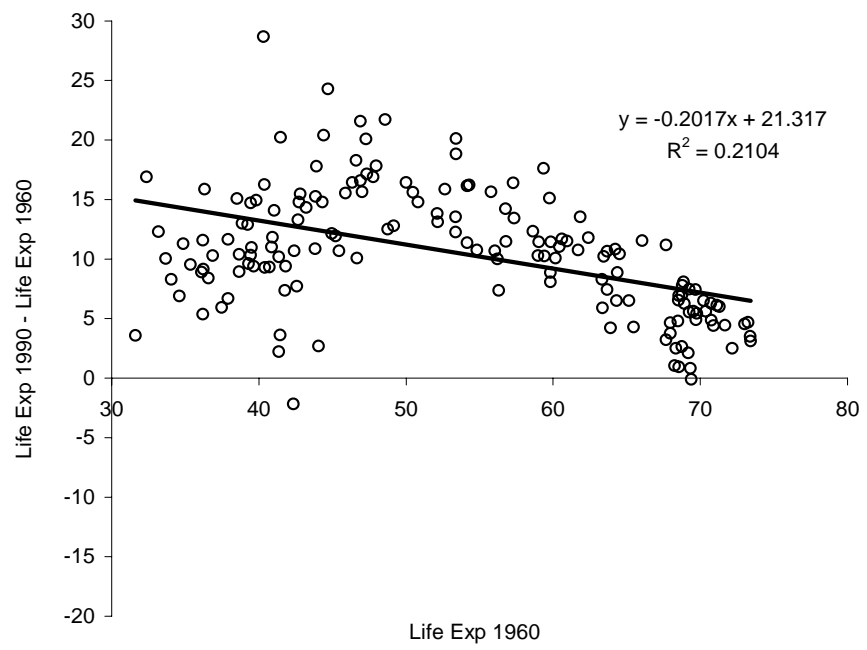

(b) $1990-2000$

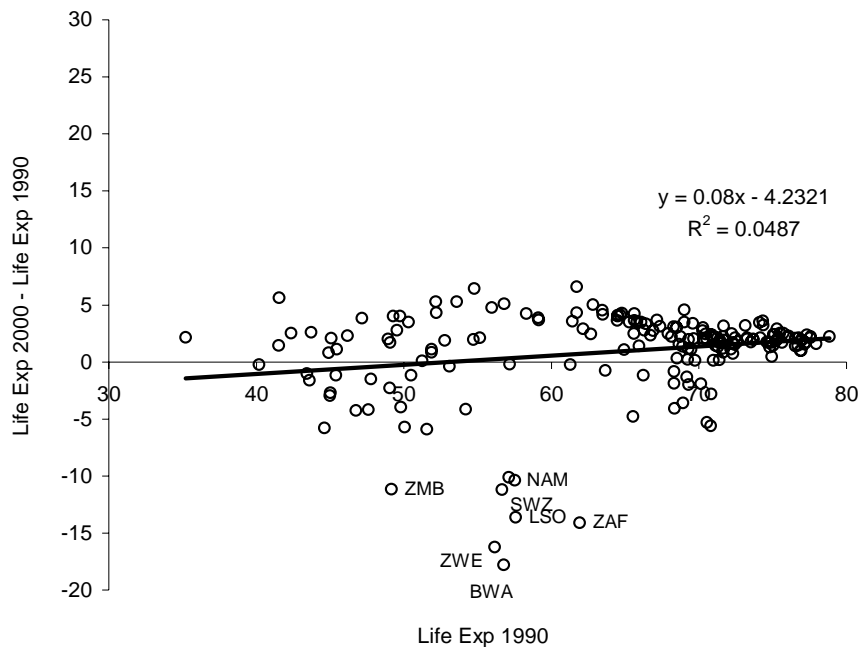


Figure 4: Cross-Country Regression to the Mean in Life Expectancy, Five-Year Intervals, 1960-2000

(a) $1960-1965$

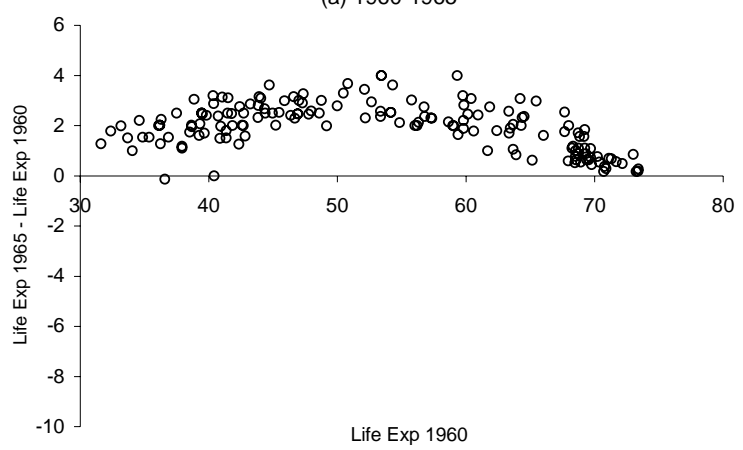

(c) $1970-1975$

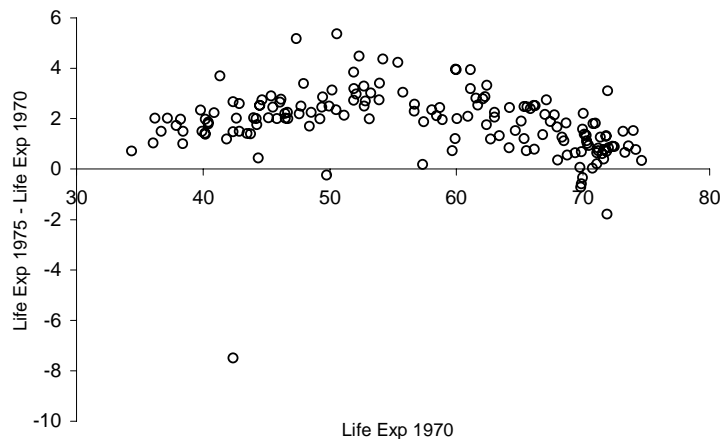

(e) $1980-1985$

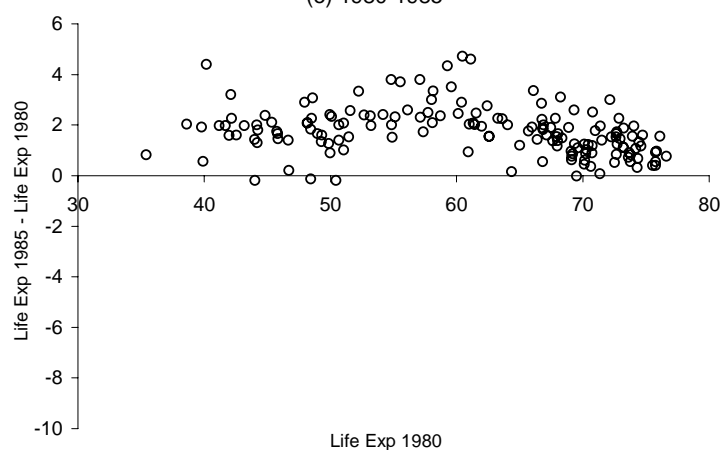

(g) 1990-1995

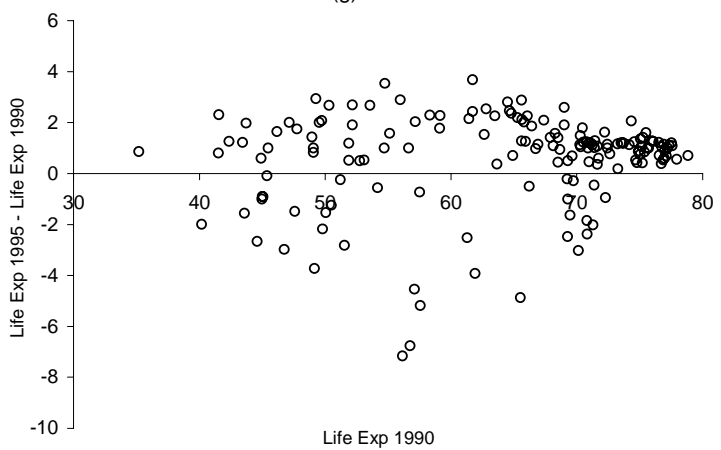

(b) $1970-1965$

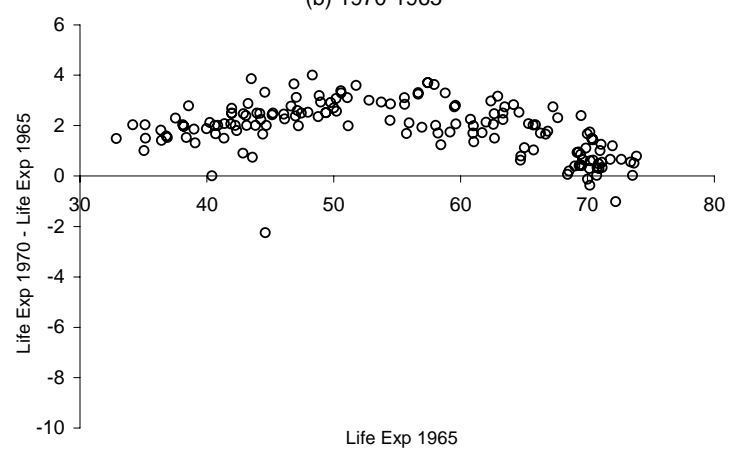

(d) $1975-1980$

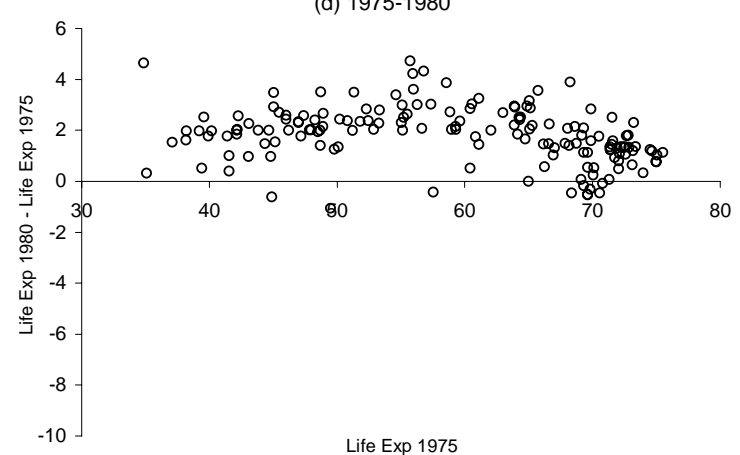

(f) $1985-1990$

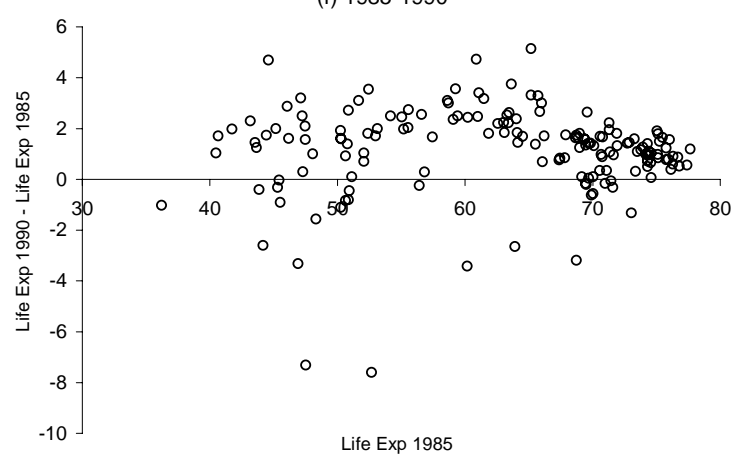

(h) $1995-2000$

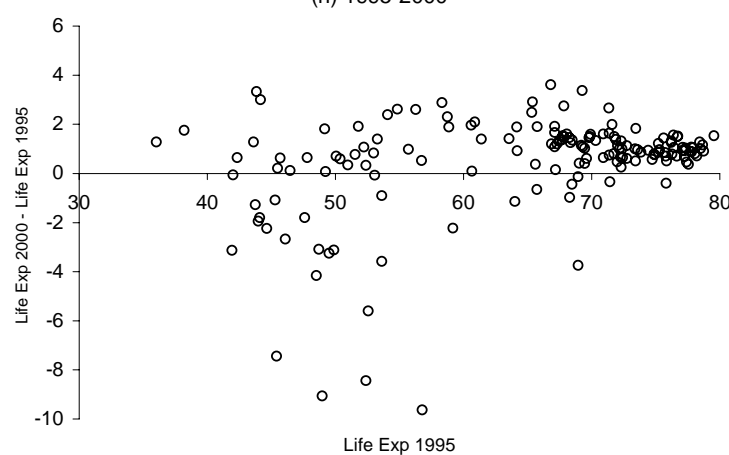


Figure 5: The Relantionship between Income and Nutrition; 1960, 1990, and 2000

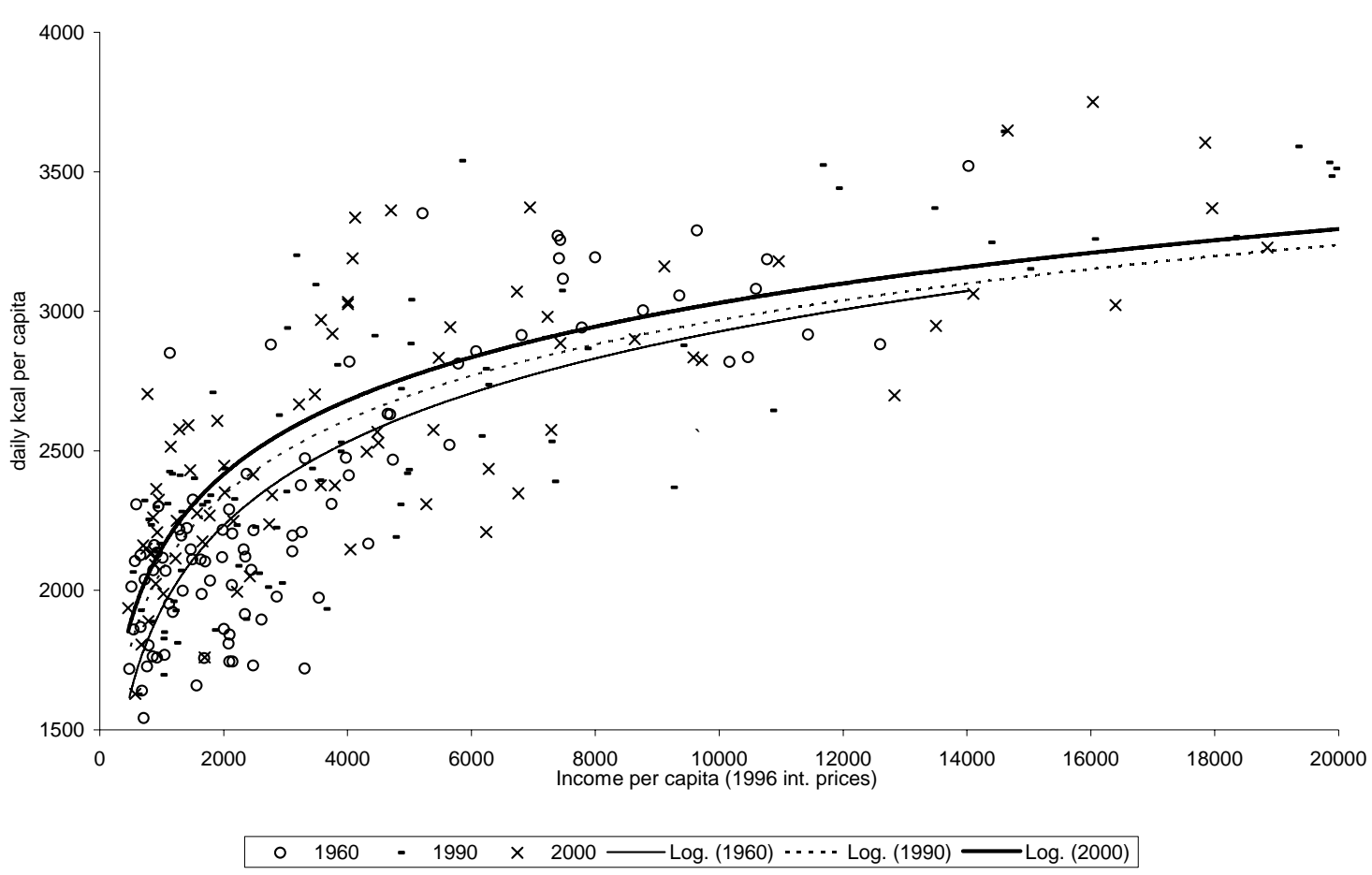

Figure 6: The Relantionship between Nutrition and Life Expectancy; 1960, 1990, and 2000

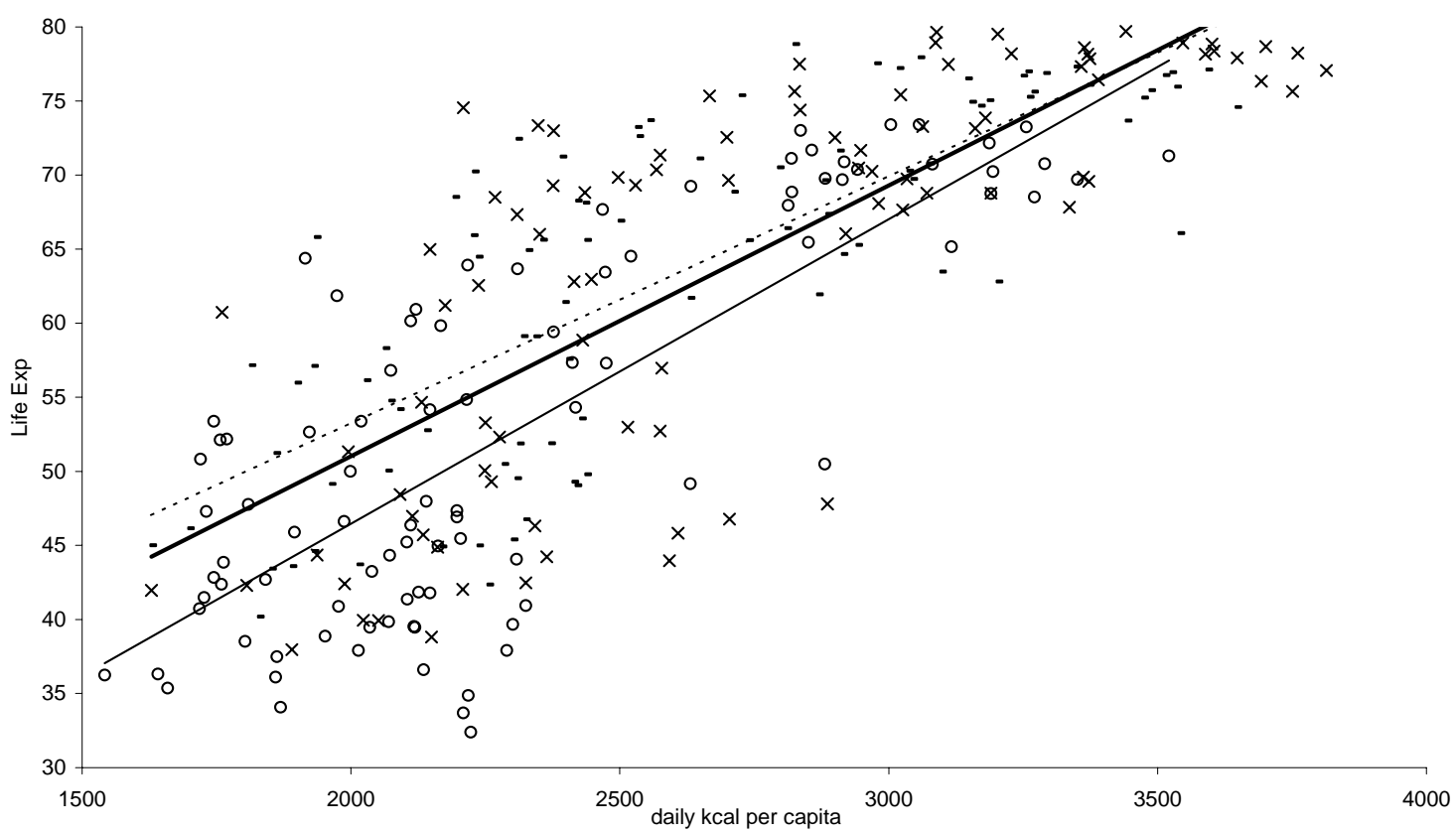

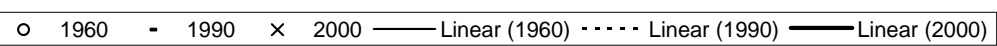


Table 1: Evolution of Cross-Country Inequality in Income and Life Expectancy, 1960-2000

\begin{tabular}{|c|c|c|c|c|c|c|}
\hline & \multicolumn{3}{|c|}{ Income per Capita } & \multicolumn{3}{|c|}{ Life Expectancy } \\
\hline & 1960 & 1990 & 2000 & 1960 & 1990 & 2000 \\
\hline Relative Mean Dev & 0.4751 & 0.4733 & 0.4215 & 0.1179 & 0.0507 & 0.0509 \\
\hline Coeff of Variation & 1.2344 & 1.2529 & 1.1662 & 0.2629 & 0.1245 & 0.1361 \\
\hline Std Dev of Logs & 1.0178 & 1.0300 & 0.9620 & 0.2552 & 0.1326 & 0.1513 \\
\hline Gini Coeff & 0.5104 & 0.5187 & 0.4873 & 0.1293 & 0.0690 & 0.0730 \\
\hline $\begin{array}{l}\text { Regression to the Mean } \\
\text { over Previous Date }\end{array}$ & & $\begin{array}{c}-0.0069 \\
(p-v a l u e=0.86)\end{array}$ & $\begin{array}{c}-0.0741 \\
(p-\text { value }=0.00)\end{array}$ & & $\begin{array}{c}-0.6133 \\
\text { (p-value }=0.00)\end{array}$ & $\begin{array}{c}0.0364 \\
\text { (p-value }=0.31)\end{array}$ \\
\hline $\begin{array}{l}\text { Note: Income per capita is } \\
\text { expectancy is life expectan } \\
\text { population (abstracting fron } \\
\text { population. Regression to th }\end{array}$ & $\overline{\mathrm{pe}}$ & $\begin{array}{l}\text { in } 1996 \text { intern } \\
\text { rld Developm } \\
\text { inequality). } \\
\text { efficient of a } \\
\text { veighted regre }\end{array}$ & $\begin{array}{l}\text { l prices, adjust } \\
\text { ndicators, Worl } \\
\text { le includes } 96 \\
\text { sion of the chat }\end{array}$ & ies, & $\begin{array}{l}\text { ising more th } \\
\text { e over the pe }\end{array}$ & $\begin{array}{l}\text { Tables } 6.1) . \mathrm{L} \\
\text { ighted by coun } \\
82 \% \text { of the wo } \\
\text { on its initial le }\end{array}$ \\
\hline
\end{tabular}

Table 2: Mean Life Expectancy at Birth of Countries in Various Ranges of National Income and Calorie Consumption, 1940 and 1970

\begin{tabular}{|c|c|c|c|c|c|c|}
\hline \multirow{3}{*}{$\begin{array}{l}\text { Daily } \\
\text { Calories } \\
\text { Per Capita }\end{array}$} & \multicolumn{6}{|c|}{ National Income per Capita in 1970 U.S. Dollars } \\
\hline & & & & & & \\
\hline & & $<150$ & $150-299$ & $300-699$ & $>700$ & All Income Levels \\
\hline \multirow[t]{2}{*}{$<2,100$} & 1970 & 42.7 & 51.5 & 53.3 & 69.5 & 47.5 \\
\hline & 1940 & 38.3 & 36.0 & & & 37.9 \\
\hline \multirow[t]{2}{*}{$2,100-2,399$} & 1970 & 42.6 & 49.9 & 56.2 & 71.4 & 49.1 \\
\hline & 1940 & 40.0 & 43.9 & 46.1 & & 43.4 \\
\hline \multirow[t]{2}{*}{$2,400-2,899$} & 1970 & 45.4 & 57.9 & 61.3 & 68.0 & 61.4 \\
\hline & 1940 & & 44.1 & 50.4 & 59.6 & 51.1 \\
\hline \multirow[t]{2}{*}{$>2,900$} & 1970 & & & & 71.6 & 71.6 \\
\hline & 1940 & & & 58.7 & 65.2 & 64.0 \\
\hline \multirow[t]{2}{*}{ All Calories Levels } & 1970 & 42.7 & 52.4 & 57.8 & 70.8 & 55.9 \\
\hline & 1940 & 38.6 & 42.4 & 52.2 & 64.1 & 52.2 \\
\hline
\end{tabular}

Source: Preston (1980, Table 5.4, p.305).

Note: 1970 countries appear in the top rows, 1940 countries in the bottom rows. 
Table 3: Diseases Responsible for Mortality Declines in Less Developed Countries and Methods Used against Them, 1900-1970

\begin{tabular}{|c|c|c|c|c|}
\hline $\begin{array}{l}\text { Dominant } \\
\text { Mode of } \\
\text { Transmission }\end{array}$ & Disease & $\begin{array}{c}\text { Approx. \% of Mort. } \\
\text { Decline in Less Dev } \\
\text { Countries } \\
\text { Accounted for } \\
\end{array}$ & $\begin{array}{l}\text { Principal Methods of } \\
\text { Prevention Deployed }\end{array}$ & $\begin{array}{l}\text { Principal } \\
\text { Methods of } \\
\text { Treatment } \\
\text { Deployed } \\
\end{array}$ \\
\hline \multirow[t]{6}{*}{ Airborne } & $\begin{array}{c}\text { Influenza/ Pneumonia/ } \\
\text { Bronchitis }\end{array}$ & 30 & & Antibiotics \\
\hline & Respiratory tuberculosis & 10 & $\begin{array}{l}\text { Immunization; identification } \\
\text { and isolation }\end{array}$ & Chemotherapy \\
\hline & Smallpox & 2 & Immunization & Chemotherapy \\
\hline & Measles & 1 & Immunization & Antibiotics \\
\hline & Diphtheria/Whooping cough & 2 & Immunization & Antibiotics \\
\hline & Total & 45 & & \\
\hline \multirow[t]{4}{*}{$\begin{array}{l}\text { Water-, food-, } \\
\text { and feces- } \\
\text { borne }\end{array}$} & $\begin{array}{l}\text { Diarrhea, enteritis, } \\
\text { gastroenteritis }\end{array}$ & 7 & $\begin{array}{l}\text { Purification and increased } \\
\text { supply of water; sewage } \\
\text { disposal; personal sanitation }\end{array}$ & Rehydration \\
\hline & Typhoid & 1 & $\begin{array}{l}\text { Purification and increased } \\
\text { supply of water; sewage } \\
\text { disposal; personal sanitation; } \\
\text { partially effective vaccine }\end{array}$ & $\begin{array}{l}\text { Rehydration, } \\
\text { antibiotics }\end{array}$ \\
\hline & Cholera & 1 & $\begin{array}{l}\text { Purification and increased } \\
\text { supply of water; sewage } \\
\text { disposal; personal sanitation; } \\
\text { partially effective vaccine; } \\
\text { quarantine }\end{array}$ & Rehydration \\
\hline & Total & 9 & & \\
\hline \multirow[t]{4}{*}{ Insect-borne } & Malaria & $13-33$ & $\begin{array}{c}\text { Insecticides, drainage, } \\
\text { larvicides }\end{array}$ & Quinine drugs \\
\hline & Typhus & 1 & $\begin{array}{l}\text { Insecticides, partially effective } \\
\text { vaccine }\end{array}$ & Antibiotics \\
\hline & Plague & 1 & $\begin{array}{c}\text { Insecticides, rat control, } \\
\text { quarantine }\end{array}$ & \\
\hline & Total & $15-33$ & & \\
\hline
\end{tabular}

Source: Preston (1980, Table 5.3, p.300). 
Table 4: Decomposition of Life Expectancy Gains by Cause of Death and Age Group, Regions of the World, 1965-1995

\begin{tabular}{|c|c|c|c|c|c|}
\hline Change in Life Expectancy & $\begin{array}{l}\text { Europe \& } \\
\text { Cent. Asia }\end{array}$ & $\begin{array}{l}\text { E. Asia \& } \\
\text { Pacific }\end{array}$ & $\begin{array}{l}\text { Latin Am. \& } \\
\text { the Carib. }\end{array}$ & $\begin{array}{l}\text { Middle East \& } \\
\text { N. Africa }\end{array}$ & $\begin{array}{c}\text { North } \\
\text { America }\end{array}$ \\
\hline Total & 8.6 & 5.4 & 10.2 & 18.0 & 5.8 \\
\hline $\begin{array}{l}\text { Decomposition by Main Causes of Death: } \\
\text { Infectious }\end{array}$ & $10 \%$ & $7 \%$ & $11 \%$ & $0 \%$ & $1 \%$ \\
\hline $\begin{array}{l}\text { Nervous system and senses } \\
\text { organs }\end{array}$ & $27 \%$ & $26 \%$ & $9 \%$ & $1 \%$ & $20 \%$ \\
\hline Heart and circulatory & $-2 \%$ & $0 \%$ & $-4 \%$ & $-9 \%$ & $39 \%$ \\
\hline Respiratory and digestive & $15 \%$ & $19 \%$ & $34 \%$ & $67 \%$ & $8 \%$ \\
\hline $\begin{array}{l}\text { Congenit. Anomal. \& perinatal } \\
\text { cond. }\end{array}$ & $9 \%$ & $19 \%$ & $11 \%$ & $14 \%$ & $17 \%$ \\
\hline Decomposition by Age Group: & & & & & \\
\hline Between 0 and 19 & $28 \%$ & $41 \%$ & $58 \%$ & $90 \%$ & $26 \%$ \\
\hline Between 20 and 49 & $14 \%$ & $7 \%$ & $14 \%$ & $5 \%$ & $10 \%$ \\
\hline 50 and above & $53 \%$ & $49 \%$ & $23 \%$ & $3 \%$ & $61 \%$ \\
\hline
\end{tabular}

Note: Calculated from Table 4 in Becker et al (2005). Decomposition of life expectancy calculated by the authors based on age and cause specific mortality data from the World Health Organization. Regional averages weighted by country population. Sample includes 49 countries.

Table 5: Age Specific Mortality Rates, World Regions

\begin{tabular}{l|cc|cc|cc}
\hline \hline Regions & \multicolumn{2}{|c|}{$\begin{array}{c}\text { Mortality rate, } \\
\text { infant (p. 1,000 } \\
\text { live births) }\end{array}$} & \multicolumn{2}{c|}{$\begin{array}{c}\text { Mort. rate, under- } \\
\text { (p. 1,000 live } \\
\text { births) }\end{array}$} & $\begin{array}{c}\text { Mortality rate, } \\
\text { adult (per 1,000 } \\
\text { adults) }\end{array}$ \\
\hline & 1960 & 2000 & 1960 & 2000 & 1960 & 2000 \\
\hline Europe and Central Asia & 45 & 16 & 56 & 20 & 160 & 165 \\
East Asia \& Pacific & 130 & 30 & 195 & 39 & 560 & 150 \\
Latin Am. \& the Carib. & 97 & 27 & 149 & 33 & 269 & 173 \\
Middle East \& North Africa & 157 & 41 & 252 & 50 & 299 & 165 \\
North America & 26 & 7 & 30 & 8 & 177 & 111 \\
South Asia & 145 & 70 & 243 & 96 & 425 & 228 \\
Sub-Saharan Africa & 149 & 102 & 247 & 165 & 498 & 492 \\
\hline \hline
\end{tabular}

Source: World Bank (2005). 
Table 6: Health Expenditures and Infrastructure, World Regions

\begin{tabular}{|c|c|c|c|c|c|c|c|c|c|c|}
\hline \multirow[t]{2}{*}{ Regions } & \multicolumn{2}{|c|}{$\begin{array}{c}\text { Health } \\
\text { expenditure, } \\
\text { private (\% } \\
\text { GDP) }\end{array}$} & \multicolumn{2}{|c|}{$\begin{array}{c}\text { Health } \\
\text { expenditure, } \\
\text { public (\% } \\
\text { GDP) }\end{array}$} & \multicolumn{2}{|c|}{$\begin{array}{c}\text { Hospital beds } \\
\text { (per } 1,000 \\
\text { people) }\end{array}$} & \multicolumn{2}{|c|}{$\begin{array}{c}\text { Access to } \\
\text { improved } \\
\text { sanitation (\% } \\
\text { pop.) } \\
\end{array}$} & \multicolumn{2}{|c|}{$\begin{array}{l}\text { Access to } \\
\text { treated watel } \\
\text { (\% of pop.) }\end{array}$} \\
\hline & 1990 & 2000 & 1990 & 2000 & 1960 & 1995 & 1990 & 2000 & 1990 & 2000 \\
\hline $\begin{array}{l}\text { Europe and } \\
\text { Central Asia } \\
\text { East Asia \& }\end{array}$ & 1.3 & 1.9 & 4.7 & 4.8 & 8.4 & 8.4 & 96 & 93 & 93 & 93 \\
\hline $\begin{array}{l}\text { Pacific } \\
\text { Latin Am. \& }\end{array}$ & 1.5 & 2.8 & 2.0 & 2.0 & 3.9 & 3.3 & 36 & 47 & 72 & 77 \\
\hline $\begin{array}{l}\text { the Carib. } \\
\text { Middle East }\end{array}$ & 3.5 & 3.5 & 2.4 & 3.4 & 3.4 & 2.4 & 72 & 77 & 82 & 86 \\
\hline $\begin{array}{l}\& \text { N. Africa } \\
\text { North }\end{array}$ & 2.3 & 2.3 & 1.9 & 2.5 & 1.9 & 1.9 & 74 & 85 & 86 & 88 \\
\hline America & 6.9 & 6.8 & 5.3 & 5.8 & 8.9 & 4.2 & 100 & 100 & 100 & 100 \\
\hline South & 3.3 & 3.7 & 0.9 & 1.0 & 0.5 & 0.5 & 22 & 34 & 72 & 84 \\
\hline $\begin{array}{l}\text { Sub-Saharan } \\
\text { Africa }\end{array}$ & 2.1 & 2.4 & 1.5 & 1.8 & 1.4 & 0.7 & 54 & 53 & 53 & 58 \\
\hline
\end{tabular}

Source: World Bank (2005).

Table 7: Inputs and other Indicators of Child Health, World Regions

\begin{tabular}{|c|c|c|c|c|c|c|c|c|}
\hline \multirow[t]{2}{*}{ Regions } & \multicolumn{2}{|c|}{$\begin{array}{c}\text { Immuniz., DPT (\% } \\
\text { of children }<1 \\
\text { year })\end{array}$} & \multicolumn{2}{|c|}{$\begin{array}{c}\text { Immuniz., measles } \\
\text { (\% of child. }<1 \\
\text { year) }\end{array}$} & \multicolumn{2}{|c|}{$\begin{array}{l}\text { Low-birthweight } \\
\text { babies (\% of } \\
\text { births) }\end{array}$} & \multicolumn{2}{|c|}{$\begin{array}{l}\text { Malnutrition prev. } \\
\text { (\% of child. under } \\
5 \text { ) }\end{array}$} \\
\hline & 1980 & 2000 & 1980 & 2000 & 1980 & 1995 & 1985 & 1995 \\
\hline $\begin{array}{l}\text { Europe and } \\
\text { Central Asia } \\
\text { East Asia \& }\end{array}$ & 77 & 94 & 54 & 90 & 5.9 & 7.0 & .. & 17.4 \\
\hline $\begin{array}{l}\text { Pacific } \\
\text { Latin Am. \& the }\end{array}$ & 38 & 85 & 34 & 86 & 11.8 & 10.8 & 42.5 & 31.0 \\
\hline $\begin{array}{l}\text { Carib. } \\
\text { Middle East \& }\end{array}$ & 43 & 87 & 47 & 92 & 8.0 & 9.3 & 24.7 & 18.5 \\
\hline North Africa & 39 & 91 & 34 & 93 & 7.1 & 12.0 & 21.2 & 22.3 \\
\hline No & 96 & 95 & 93 & 92 & 6.6 & 7.2 &.. & 2.0 \\
\hline South Asia & 8 & 61 & 2 & 56 & 22.4 & 31.2 & 60.1 & 49.9 \\
\hline $\begin{array}{l}\text { Sub-Saharan } \\
\text { Africa }\end{array}$ & 17 & 52 & 24 & 56 & 16.7 & 13.3 & 29.1 & 36.8 \\
\hline
\end{tabular}

Source: World Bank (2005). 